\title{
Discovery of a Novel Series of Potent and Selective Alkynylthiazole-Derived PI3K $\gamma$ Inhibitors
}

Upul K. Bandarage*, Alex M. Aronov, Jingrong Cao, Jon H. Come, Kevin M. Cottrell, Robert J. Davies, Simon Giroux, Marc Jacobs, Sudipta Mahajan, David Messersmith, Cameron S. Moody, Rebecca Swett, Jinwang Xu.

Vertex Pharmaceuticals Incorporated, 50 Northern Avenue, Boston, Massachusetts 02210, United States

\section{Content}

Experimental section............................................ 1 23

Description biochemical assay...............................S24-S22

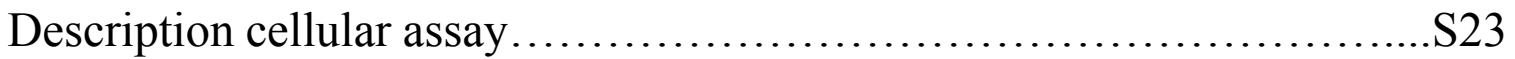

Air pouch protocol...............................................S24

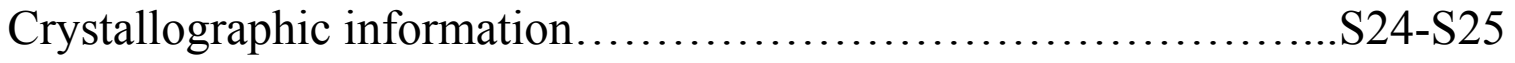

Kinase selectivity profile of compounds $4, \mathbf{1 4}, \mathbf{2 3}, \mathbf{3 1}$ and $\mathbf{3 2} \ldots \ldots \ldots . \quad$ S25

MDCK-MDR1 Permeability Assay ................................S26

\section{EXPERIMENTAL SECTION}

All commercially available reagents and anhydrous solvents were used without further purification. Purity assessment for final compounds based on analytical HPLC: column, 4.6 x $50 \mathrm{~mm}$ Waters YMC Pro-C18 column, $5 \mu \mathrm{M}, 120 \AA$. Mobile phases are as follows: A, water with $0.2 \%$ formic acid; B, acetonitrile with $0.2 \%$ formic acid; gradient, $10-90 \%$ B in $3 \mathrm{~min}$ with $5 \mathrm{~min}$ run time. The flow rate is $1.5 \mathrm{~mL} / \mathrm{min}$. All compounds were $\geq 95 \%$ purity. Mass samples were analyzed on a Waters/MicroMass ZQ, ZMD, Quattro LC, or 
Quatro II mass spectrometer operated in a single MS mode with electrospray ionization. Samples were introduced into the mass spectrometer using flow injection (FIA) or chromatography. The mobile phase for all mass analysis consisted of acetonitrile-water mixtures with either $0.2 \%$ formic acid or ammonium formate. High-resolution mass measurements were performed on a Thermo Q Exactive mass spectrometer with a heated electrospray source operated in positive ion mode. 1H NMR spectra were recorded either using a Bruker Avance 400 (400 MHz) or a Bruker Avance II-300 (300 MHz) instrument and are quoted in ppm relative to a tetramethylsilane internal standard, or by referencing on the chemical shift of the deuterated solvent. The column chromatography was performed using Teledyne ISCO RediSep Normal Phase (35-70 microns) or RediSep Gold Normal Phase (25-40 microns) silica flash columns using a Teledyne ISCO Combiflash Companion or Combiflash $\mathrm{Rf}$ purification system. Preparative reversed phase chromatography was carried out using a Gilson 215 liquid handler coupled to a UV-Vis 156 Gilson detector, an Agilent Zorbax SB-C18 column, 21.2 x 100 mm, a linear gradient from $10-90 \%$ acetonitrile in water over $10 \mathrm{~min}(0.1 \% \mathrm{TFA})$; the flow rate was $20 \mathrm{~mL} / \mathrm{min}$. Microwave-assisted reactions were performed using a CEM Discover S-Class microwave instrument (single mode microwave reactor) with 48-position autosampler. Temperature was monitored during microwave reactions by a vertically sensored infrared temperature sensor, which comes as a standard feature of the CEM Discover S-Class system.

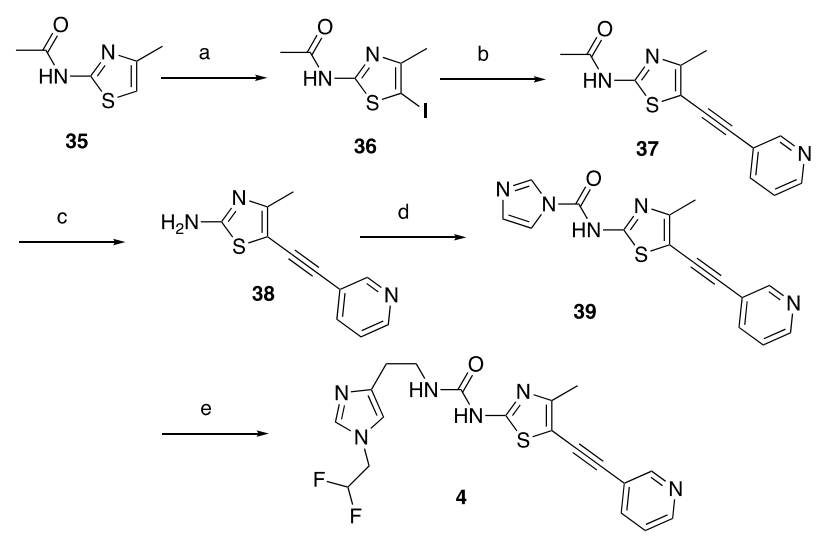

Reagents and conditions. (a) NIS, DCM, r.t., $10 \mathrm{~min}, 66 \%$ (b) 3-ethynylpyridine, $\operatorname{Pd}\left(\mathrm{PPh}_{3}\right)_{4}, \mathrm{CuI}, \mathrm{Et}_{3} \mathrm{~N}$, dioxane, r.t., $1.5 \mathrm{~h}, 77 \%$ (c) hydrazine hydrate, THF, $85^{\circ} \mathrm{C}, 6 \mathrm{~h}, 77 \%$ (d) CDI, DMF, $70{ }^{\circ} \mathrm{C}, 2 \mathrm{~h}, 92 \%$ (e) 2-(1-(2,2-difluoroethyl)- $1 H$-imidazol-4-yl)ethan-1amine, $\mathrm{Et}_{3} \mathrm{~N}$, THF, r.t., 20 h, $58 \%$. 


\section{$N$-(5-Iodo-4-methyl-thiazol-2-yl)acetamide (36)}

To a stirred solution of $N$-(4-methylthiazol-2-yl)acetamide, 35 (5.2 g, $33.33 \mathrm{mmol})$ in acetonitrile (100 mL) was added NIS $(8.98 \mathrm{~g}, 39.95 \mathrm{mmol})$ in small portions at room temperature. The resultant suspension was stirred at room temperature for 10 min. The precipitate was collected by filtration and the precipitate was washed with cold $\mathrm{CH}_{3} \mathrm{CN}$ (25 mL), dried in high vacuum for $6 \mathrm{~h}$ to afford compound 36 (6.2 $\mathrm{g}$, 66\%) as offwhite solid. ${ }^{1} \mathrm{H}$ NMR (300 MHz, DMSO-d 6 ) $\delta 12.24(\mathrm{~s}, 1 \mathrm{H}), 2.57(\mathrm{~s}, 3 \mathrm{H}), 2.12$ (s, 3H). mass spectrum (ESI) m/z 283.0 [M $+\mathrm{H}]^{+}\left(\mathrm{C}_{6} \mathrm{H}_{7} \mathrm{IN}_{2} \mathrm{OS}\right)$ requires 282.9.

\section{N-(4-Methyl-5-(pyridin-3-ylethynyl)thiazol-2-yl)acetamide (37)}

Compound 36 (500 mg, $1.77 \mathrm{mmol}$ ) and 3-ethynylpyridine (228 mg, $2.22 \mathrm{mmol}$ ) were stirred in THF (5 mL). After purging the solution with $\mathrm{N}_{2}, \mathrm{CuI}(34 \mathrm{mg}, 0.177 \mathrm{mmol})$ and bis(triphenylphosphine)palladium(II) chloride (124 mg, $0.177 \mathrm{mmol})$ were added, followed by the addition of $\mathrm{Et}_{3} \mathrm{~N}(538 \mathrm{mg}, 5.32 \mathrm{mmol})$. The reaction mixture was stirred at RT for $1.5 \mathrm{~h}$. The reaction mixture was filtered and the volatiles were removed under reduced pressure to produce compound 37 (300 mg, 77\%): ${ }^{1} \mathrm{HNMR}$ (DMSO- $\left.d_{6}\right) \delta 12.43$ $(\mathrm{s}, 1 \mathrm{H}), 8.74(\mathrm{~s}, 1 \mathrm{H}), 8.57(\mathrm{~d}, J=2.9 \mathrm{~Hz}, 1 \mathrm{H}), 7.96(\mathrm{~d}, J=8.0 \mathrm{~Hz}, 1 \mathrm{H}), 7.46(\mathrm{dd}, J=4.8$, $7.9 \mathrm{~Hz}, 1 \mathrm{H}), 2.41(\mathrm{~s}, 3 \mathrm{H})$, and $2.16(\mathrm{~s}, 3 \mathrm{H})$; mass spectrum $(\mathrm{ESI}) \mathrm{m} / \mathrm{z}[\mathrm{M}+\mathrm{H}]^{+} 258.1$ $\left(\mathrm{C}_{13} \mathrm{H}_{11} \mathrm{~N}_{3} \mathrm{OS}\right)$ requires 258.2.

\section{4-Methyl-5-(pyridin-3-ylethynyl)thiazol-2-amine (38)}

The compound $37(400 \mathrm{mg}, 1.56 \mathrm{mmol})$ was stirred in hydrazine hydrate at $70{ }^{\circ} \mathrm{C}$ for 20

minutes and water $(5 \mathrm{~mL})$ was added. The resulting precipitate was filtered, washed with water and dried under high vacuum to afford compound $\mathbf{3 8}(260 \mathrm{mg}, 77 \%)$. mass spectrum (ESI) $\mathrm{m} / \mathrm{z}[\mathrm{M}+\mathrm{H}]^{+} 216.3\left(\mathrm{C}_{11} \mathrm{H}_{9} \mathrm{~N}_{3} \mathrm{~S}\right)$ requires 216.1 .

N-(4-Methyl-5-(pyridin-3- ylethynyl)thiazol-2-yl)- 1H-imidazole- 1-carboxamide (39) Compound 38 (91 mg, $0.423 \mathrm{mmol}$ ), 1,1'carbonyldiimidazole (103 mg, $0.634 \mathrm{mmol}$ ), and 
triethylamine $(85.6 \mathrm{mg}, 0.845 \mathrm{mmol})$ were stirred in DMF $(2.1 \mathrm{~mL})$ at $70{ }^{\circ} \mathrm{C}$ for $2 \mathrm{~h}$. MTBE was added and the resulting precipitate collected by filtration to produce $N$-(4-methyl-5(pyridin-3- ylethynyl)thiazol-2-yl)- 1H-imidazole- 1-carboxamide, 39 (120 mg, 92\%).

\section{1-(2-(1-(2,2-Difluoroethyl)- $1 H$ imidazol- 4-yl)ethyl)-3-(4-methyl-5-(2-(pyridin-3- yl)ethynyl)thiazol-2-yl)urea (4)}

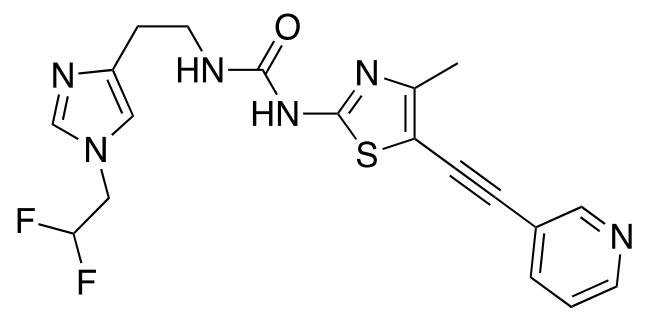

A solution of compound 39 (25 mg, $0.08 \mathrm{mmol})$ and 2-(1-(2,2-difluoroethyl)-1H-imidazol4-yl)ethanamine $(80 \mathrm{mg}, 0.32 \mathrm{mmol})$ and $\mathrm{Et}_{3} \mathrm{~N}(0.112 \mathrm{~mL})$ in DCM $(0.4 \mathrm{~mL})$ was stirred for $20 \mathrm{~h}$ at RT. The reaction mixture was filtered, treated with cold methyl $t$-butylether and filtered once more. The filtrate was concentrated under reduced pressure and purified by medium pressure silica gel chromatography $(0-10 \% \mathrm{MeOH} / \mathrm{DCM})$ to afford compound 4 (19.5 mg, 58\%) ${ }^{1} \mathrm{H}$ NMR (DMSO- $\left.d_{6}\right): 10.84(\mathrm{~s}, 1 \mathrm{H}), 8.71(\mathrm{~d}, J=1.5 \mathrm{~Hz}, 1 \mathrm{H}), 8.55$ (dd, $J=1.6,4.9 \mathrm{~Hz}, 1 \mathrm{H}), 8.18(\mathrm{~s}, 1 \mathrm{H}), 7.94(\mathrm{dt}, J=7.9,2.5 \mathrm{~Hz}, 1 \mathrm{H}), 7.44$ (dd, $J=4.9,7.9 \mathrm{~Hz}$, 1H), $7.20(\mathrm{~s}, 1 \mathrm{H}), 6.72(\mathrm{~s}, 1 \mathrm{H}), 6.64-6.37(\mathrm{~m}, 1 \mathrm{H}), 4.60(\mathrm{dt}, J=2.9,15.9 \mathrm{~Hz}, 2 \mathrm{H}), 3.40$ $(\mathrm{m}, 2 \mathrm{H}), 2.73(\mathrm{t}, J=6.8 \mathrm{~Hz}, 2 \mathrm{H}), 2.35(\mathrm{~s}, 3 \mathrm{H})$. HRMS: m/z calcd for $\mathrm{C}_{19} \mathrm{H}_{18} \mathrm{~F}_{2} \mathrm{~N}_{6} \mathrm{OS}\left[\mathrm{M}^{+}+\right.$ $1]^{+}$417.1231; found 417.1313.

Scheme 3. Synthesis of Compound 6 

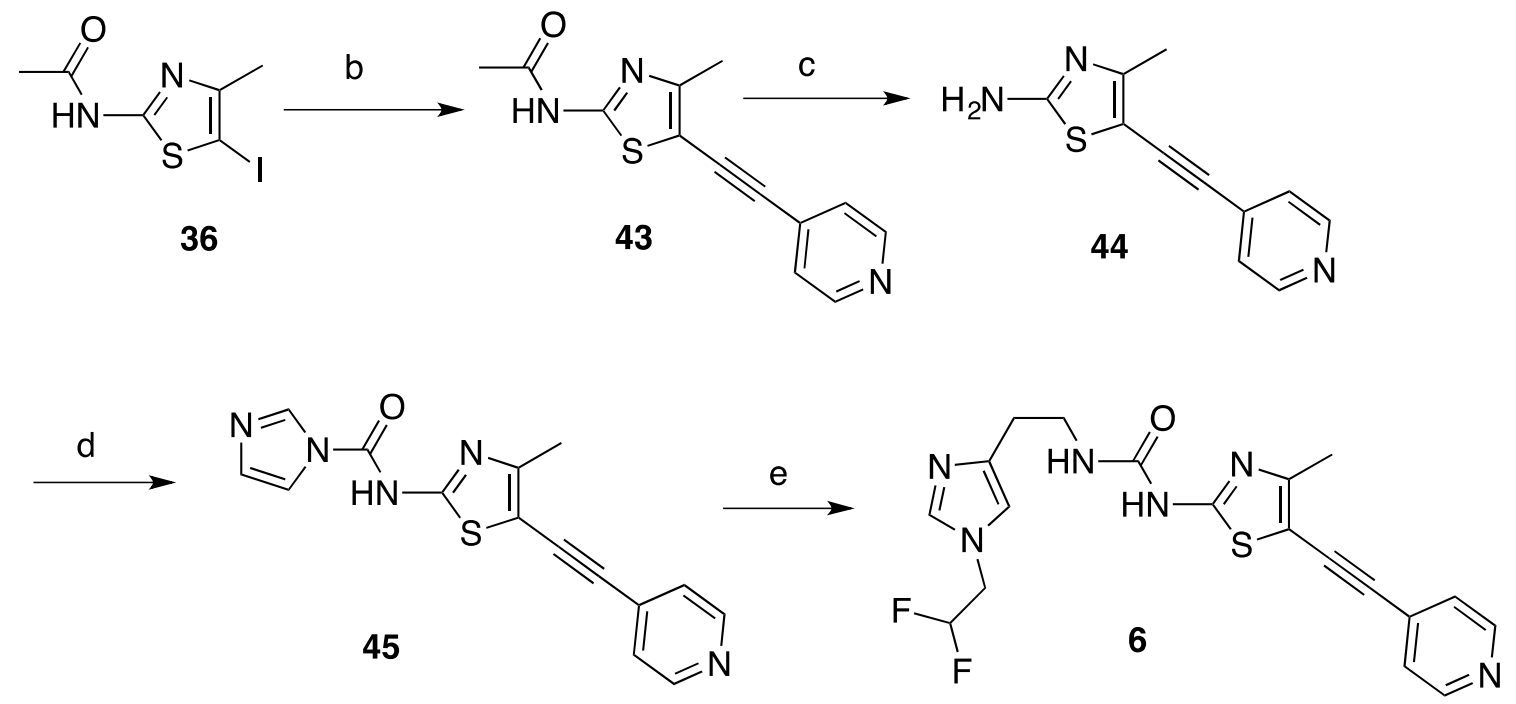

Reagents and conditions. (a) 4-ethynylpyridine, $\mathrm{Pd}\left(\mathrm{PPh}_{3}\right)_{4}, \mathrm{CuI}, \mathrm{Et}_{3} \mathrm{~N}$, dioxane, $80{ }^{\circ} \mathrm{C}, 45$ min, $66 \%$ (b) $\mathrm{NH}_{2} \mathrm{NH}_{2} \cdot \mathrm{H}_{2} \mathrm{O}$, THF, $100{ }^{\circ} \mathrm{C}, 6 \mathrm{~h}, 76.5 \%$ (c) CDI, DMF, $65{ }^{\circ} \mathrm{C}, 1 \mathrm{~h}, 87 \%$ (d) 2-(1-(2,2-difluoroethyl)-1H-imidazol-4-yl)ethan-1-amine, Et 3 N, THF, r.t., 1 h, 44\%.

\section{Step 1: N-(4-Methyl-5-(pyridin-4-ylethynyl)thiazol-2-yl)acetamide (43)}

A solution of $N$-(4-iodo-5-methyl-thiazol-2-yl)acetamide, 36 (4 g, $14.18 \mathrm{mmol}), 4$ ethynylpyridine ( $1.609 \mathrm{~g}, 15.60 \mathrm{mmol}) \mathrm{Et}_{3} \mathrm{~N}(4 \mathrm{~mL}, 28.70 \mathrm{mmol})$ in 1,4-dioxane (10 was purged with $\mathrm{N}_{2}(5 \mathrm{~min})$ and $\mathrm{Pd}\left(\mathrm{PPh}_{3}\right)_{4}(819.3 \mathrm{mg}, 0.71 \mathrm{mmol})$ and $\mathrm{CuI}(135.0 \mathrm{mg}, 0.71$ mmol) were added. The solution was heated at $85{ }^{\circ} \mathrm{C}$ for 45 min and the solvent was evaporated under reduced pressure. Water $(50 \mathrm{~mL})$ was added and the suspension was stirred at RT 10 min to form a brown precipitate and the precipitate was filtered and washed with water $(3 \times 25 \mathrm{~mL})$ and then DCM $(3 \times 25 \mathrm{~mL})$ until a brownish yellow precipitate was formed. The product was dried in high vacuum to afford compound 43 (2.4 g, 66\%) ${ }^{1} \mathrm{HNMR}(300 \mathrm{MHz}, \mathrm{DMSO}) \delta 12.45$ (s, 1H), 8.60 (d, $\left.J=5.2 \mathrm{~Hz}, 2 \mathrm{H}\right), 7.49$ (d, $J=8.0 \mathrm{~Hz}$, $2 \mathrm{H}), 2.45(\mathrm{~s}, 3 \mathrm{H}), 2.17$ (s, 3H); mass spectrum (ESI) m/z [M + H] $]^{+} 258.3\left(\mathrm{C}_{13} \mathrm{H}_{11} \mathrm{~N}_{3} \mathrm{OS}\right)$ requires 258.1 .

Step 2: 4-Methyl-5-(pyridin-4-ylethynyl)thiazol-2-amine (44) 
Hydrazine monohydrate $(25 \mathrm{~mL}, 50.52 \mathrm{mmol})$ was added to a stirred suspension of compound $43(5 \mathrm{~g}, 19.43 \mathrm{mmol})$ in THF $(75 \mathrm{~mL})$ and the solution was heated at $100{ }^{\circ} \mathrm{C}$ for $6 \mathrm{~h}$. The brown color reaction mixture was cooled to RT and concentrated under reduced pressure to give brownish yellow residue which was dissolved in warm methanol $(50 \mathrm{~mL})$ and filtered. The filtrate was concentered under reduced pressure to afford a brownish solid and the solid was decanted with ether and the ether layer was discarded. The solid was collected and dried in high vacuum for $4 \mathrm{~h}$ to afford compound 44 (3.2 $\mathrm{g}, 76.5 \%$ as a yellowish brown solid. ${ }^{1} \mathrm{H}$ NMR $\left(300 \mathrm{MHz}, \mathrm{CD}_{3} \mathrm{OD}\right) \delta 8.48(\mathrm{~d}, J=6 \mathrm{~Hz}, 2 \mathrm{H}), 7.40(\mathrm{~d}, J=$ $6.0 \mathrm{~Hz}, 2 \mathrm{H}), 2.89(\mathrm{~s}, 3 \mathrm{H})$. mass spectrum $(\mathrm{ESI}) \mathrm{m} / \mathrm{z}[\mathrm{M}+\mathrm{H}]^{+} 216.1\left(\mathrm{C}_{11} \mathrm{H}_{9} \mathrm{~N}_{3} \mathrm{~S}\right)$ requires 216.1 .

\section{Step 3: $N$-[4-Methyl-5-[2-(4-pyridyl)ethynyl]thiazol-2-yl]imidazole-1-carboxamide} (45)

A mixture of 44 (100 mg, $0.46 \mathrm{mmol})$ and di(imidazol-1-yl)methanone (75.32 mg, 0.4645 mmol) in anhydrous DCM $(5 \mathrm{~mL})$ was heated to reflux $\left(65^{\circ} \mathrm{C}\right)$ in for $1 \mathrm{~h}$ and cooled to room temperature. The solvent was evaporated under reduced pressure and anhydrous ether was added and the solid was filtered. The brown solid was washed with ether $(10 \mathrm{~mL})$ and dried in high vacuum for $2 \mathrm{~h}$ to afford compound 45 (126 mg, 87\%).

\section{Step 4: 1-(2-(1-(2,2-Difluoroethyl)-1H-imidazol-4-yl)ethyl)-3-(4-methyl-5-(pyridin-4- ylethynyl)thiazol-2-yl)urea (6).}

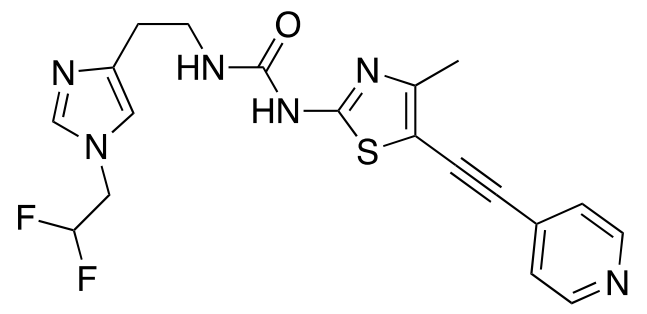

A mixture of 45 (50 mg, $0.1616 \mathrm{mmol})$, 2-[1-(2,2-difluoroethyl)imidazol-4-yl]ethanamine (33.97 $\mathrm{mg}, 0.19 \mathrm{mmol})$ and DIPEA $(30 \mu \mathrm{L})$ in THF $(1 \mathrm{~mL})$ was stirred at RT for $1 \mathrm{~h}$ and the solvent was evaporated under reduced pressure. The crude product was purified by reversed-phase chromatography (Column: C18. Gradient: 0-100\% $\mathrm{MeCN}$ in water with $0.1 \% \mathrm{HCl})$ to afford compound $\mathbf{6 . H C l}(36 \mathrm{mg}, 44.3 \%)$ as a yellow powder. $\left(\mathrm{CD}_{3} \mathrm{OD}\right): 9.00$ $(\mathrm{s}, 1 \mathrm{H}), 8.77(\mathrm{~d}, J=5.4 \mathrm{~Hz}, 2 \mathrm{H}), 8.06(\mathrm{~d}, J=5.5 \mathrm{~Hz}, 2 \mathrm{H}), 7.53(\mathrm{~s}, 1 \mathrm{H}), 6.1(\mathrm{t}, J=51 \mathrm{~Hz}$, 
1H), $4.73(\mathrm{t}, J=15 \mathrm{~Hz}, 2 \mathrm{H}), 3.58(\mathrm{~m}, 2 \mathrm{H}), 3.00(\mathrm{~m}, 2 \mathrm{H}), 2.50(\mathrm{~s}, 3 \mathrm{H}) . \mathrm{HRMS}: \mathrm{m} / \mathrm{z}$ calcd for $\mathrm{C}_{19} \mathrm{H}_{18} \mathrm{~F}_{2} \mathrm{~N}_{6} \mathrm{OS}\left[\mathrm{M}^{+}+1\right] 417.1309$; found, 417.1304.

\section{1-(2-(2-Chlorophenoxy)ethyl)-3-(4-methyl-5-(pyridin-4-ylethynyl)thiazol-2-yl)urea} (7)

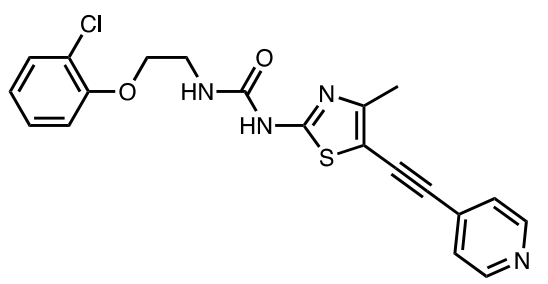

A solution of compound 45 (25 mg, $0.08 \mathrm{mmol})$ and 2-(2-chlorophenoxy)ethan-1-amine $(29 \mathrm{mg}, 0.17 \mathrm{mmol})$ and DIPEA $(0.45 \mathrm{~mL})$ in THF $(1 \mathrm{~mL})$ was stirred at room temperature for $20 \mathrm{~h}$ and the reaction mixture was filtered. The crude product was purified by reversed-phase chromatography (Column: C18. Gradient: 0 -100 \% $\mathrm{MeCN}$ in water with $0.1 \% \mathrm{HCl})$ to afford compound 7.HCl $(30 \mathrm{mg}, 40.5 \%)$ as a yellow powder. ${ }^{1} \mathrm{H} \mathrm{NMR}(300$ MHz, MeOD) $\delta 8.77(\mathrm{~d}, J=5.4 \mathrm{~Hz}, 2 \mathrm{H}), 8.06(\mathrm{~d}, J=5.5 \mathrm{~Hz}, 2 \mathrm{H}), 7.53(\mathrm{~s}, 1 \mathrm{H}), 6.10(\mathrm{t}, J$ $=51 \mathrm{~Hz}, 1 \mathrm{H}), 4.73(\mathrm{t}, J=15 \mathrm{~Hz}, 2 \mathrm{H}), 3.58(\mathrm{~m}, 2 \mathrm{H}), 3.00(\mathrm{~m}, 2 \mathrm{H}), 2.50(\mathrm{~s}, 3 \mathrm{H}) . \mathrm{HRMS}: \mathrm{m} / \mathrm{z}$ calcd for $\mathrm{C}_{20} \mathrm{H}_{17} \mathrm{ClN}_{4} \mathrm{O}_{2} \mathrm{~S}\left[\mathrm{M}^{+}+1\right] ; 413.0833$ found, 413.0839 .

\section{1-(2-Methoxyethyl)-3-(4-methyl-5-(pyridin-4-ylethynyl)thiazol-2-yl)urea (8)}

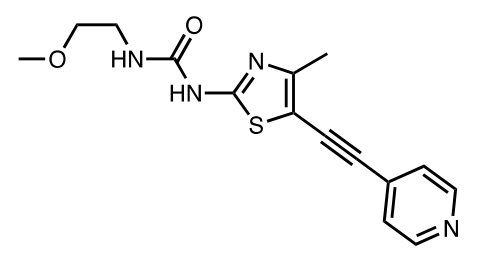

A mixture of 45 (50 mg, $0.1616 \mathrm{mmol})$, 2-methoxyethan-1-amine (18 $\mathrm{mg}, 0.24 \mathrm{mmol})$ and DIPEA (140 $\mu \mathrm{L})$ in THF (1 mL) was stirred at $\mathrm{RT}$ for $1 \mathrm{~h}$ and the solvent was evaporated under reduced pressure. The crude product was purified by reversed-phase chromatography (Column: C18. Gradient: $0-100 \% \mathrm{MeCN}$ in water with $0.1 \% \mathrm{HCl}$ ) to afford compound 8. HCl (35 mg, 60\%) as a yellow powder. ${ }^{1} \mathrm{HNMR}\left(\mathrm{CD}_{3} \mathrm{OD}\right)$ : $8.82(\mathrm{~d}, 2 \mathrm{H}), 7.98(\mathrm{~d}, 2 \mathrm{H}), 3.42-3.39(\mathrm{~m}, 2 \mathrm{H}), 3.34-3.30(\mathrm{~m}, 2 \mathrm{H}), 3.28(\mathrm{~s}, 3 \mathrm{H}), 2.43(\mathrm{~s}, 3 \mathrm{H})$. HRMS: m/z calcd for $\mathrm{C}_{15} \mathrm{H}_{16} \mathrm{~N}_{4} \mathrm{O}_{2} \mathrm{~S}\left[\mathrm{M}^{+}+1\right] 317.1065$; found 317.1068. 


\section{1-(2-Ethoxyethyl)-3-(4-methyl-5-(pyridin-4-ylethynyl)thiazol-2-yl)urea (9)}

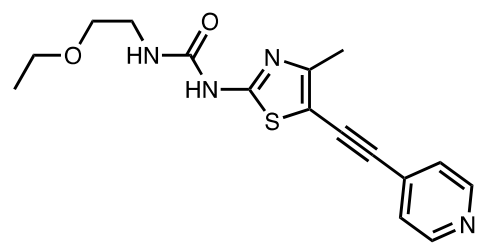

Compound 9 was synthesized in a manner similar to compound 8 using 45 and 2-ethoxyethan-1-amine to afford 9.HCl (29 mg, 48\%). ${ }^{1} \mathrm{HNMR}$ $\left(\mathrm{CD}_{3} \mathrm{OD}: 8.77(\mathrm{~s}, 2 \mathrm{H}), 8.08(\mathrm{~s}, 2 \mathrm{H}), 3.58-3.51(\mathrm{~m}, 4 \mathrm{H}), 3.44(\mathrm{t}, J=6 \mathrm{~Hz}, 2 \mathrm{H}), 2.52(\mathrm{~s}\right.$, $3 \mathrm{H}), 1.21(\mathrm{t}, J=6.0 \mathrm{~Hz}, 3 \mathrm{H}) . \mathrm{HRMS}: \mathrm{m} / \mathrm{z}$ calcd for $\mathrm{C}_{16} \mathrm{H}_{18} \mathrm{~N}_{4} \mathrm{O}_{2} \mathrm{~S}\left[\mathrm{M}^{+}+1\right] 331.1229$; found 331.1222 .

1-(4-Methyl-5-(pyridin-4-ylethynyl)thiazol-2-yl)-3-(2-propoxyethyl)urea (10)

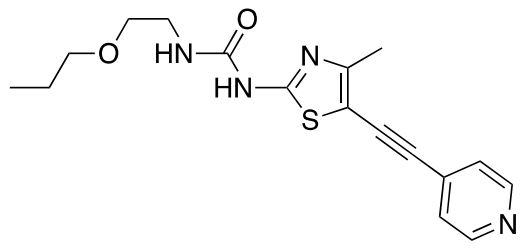

Compound 10 was synthesized in a manner similar to compound 8 using 45 and 2-propoxyethan-1-amine to afford 10. $\mathrm{HCl}(17 \mathrm{mg}, 27 \%$ ) . ${ }^{1}$ HNMR (DMSO-d $\left.)_{6}\right) 11.0$ (brs, 1H), 8.73 (d, $\left.J=3.0 \mathrm{~Hz}, 2 \mathrm{H}\right), 7.81$ (d, $\left.J=3.0 \mathrm{~Hz}, 2 \mathrm{H}\right), 6.80$ (brs, 1H), $3.46-3.30(\mathrm{~m}, 4 \mathrm{H}), 2.41(\mathrm{~s}, 3 \mathrm{H}), 2.38(\mathrm{~m}, 2 \mathrm{H}), 1.56-1.49(\mathrm{~m}, 2 \mathrm{H}), 0.88$ (t, $J=$ $9.0 \mathrm{~Hz}, 3 \mathrm{H})$. HRMS: m/z calcd for $\mathrm{C}_{17} \mathrm{H}_{20} \mathrm{~N}_{4} \mathrm{O}_{2} \mathrm{~S}\left[\mathrm{M}^{+}+1\right] 345.1386$; found 345.1388 .

1-(2-(3,3-Dimethylbutoxy)ethyl)-3-(4-methyl-5-(pyridin-4-ylethynyl)thiazol-2-yl)urea (11)

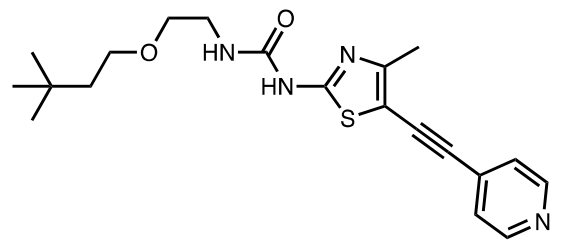

Compound 11 was synthesized in a manner similar to compound 8 using 45 and 2-propoxyethan-1-amine to afford compound 11.HCl (4.3mg, 
6\%) . ${ }^{1} \mathrm{HNMR}\left(\mathrm{DMSO}-d_{6}\right)$ :

${ }^{1} \mathrm{H}$ NMR (400 MHz, DMSO) $\delta 11.12(\mathrm{~s}, 1 \mathrm{H}), 8.81$ (brs, 2H), 7.98 - 7.86 (m, 2H), $6.91(\mathrm{t}$, $J=5.7 \mathrm{~Hz}, 1 \mathrm{H}), 3.52-3.37$ (m, 4H), 3.30 (q, $J=5.5 \mathrm{~Hz}, 2 \mathrm{H}), 2.43$ (s, 3H), 1.45 (t, $J=$ $7.4 \mathrm{~Hz}, 2 \mathrm{H}), 0.89$ (s, 9H). HRMS: $\mathrm{m} / \mathrm{z}$ calcd for $\mathrm{C}_{20} \mathrm{H}_{26} \mathrm{~N}_{4} \mathrm{O}_{2} \mathrm{~S}\left[\mathrm{M}^{+}+1\right]$ 387.1847; found 387.1849

\section{1-(2-(Cyclopropylmethoxy)ethyl)-3-(4-methyl-5-(pyridin-4-ylethynyl)thiazol-2-} yl)urea (12)

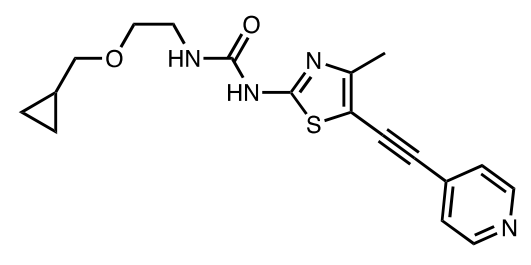

Compound 12 was synthesized in a manner similar to compound 8 using 45 and 2- to 2-(cyclopropylmethoxy)ethan-1-amine to afford 12. $\mathrm{HCl}$ (20 mg, 31\%) . ${ }^{1}$ HNMR (DMSO- $d 6$ ): $11.2(\mathrm{brs}, 1 \mathrm{H}), 8.78$ (d, $\left.J=6.0 \mathrm{~Hz}, 2 \mathrm{H}\right), 7.91$ (d, $J=$ $6.0 \mathrm{~Hz}, 2 \mathrm{H}), 6.91(\mathrm{brm}, 1 \mathrm{H}) 3.48$ - 3.44 (m, 2H), 3.34 - 3.25 (m, 4H), 2.42 (s, 3H), 1.00 $0.97(\mathrm{~m}, 1 \mathrm{H}), 0.47-0.43(\mathrm{~m}, 2 \mathrm{H}), 0.17-0.20(\mathrm{~m}, 2 \mathrm{H})$. HRMS: $\mathrm{m} / \mathrm{z}$ calcd for $\mathrm{C}_{18} \mathrm{H}_{20} \mathrm{~N}_{4} \mathrm{O}_{2} \mathrm{~S}$ $\left[\mathrm{M}^{+}+1\right] 357.1378$; found 357.1380 .

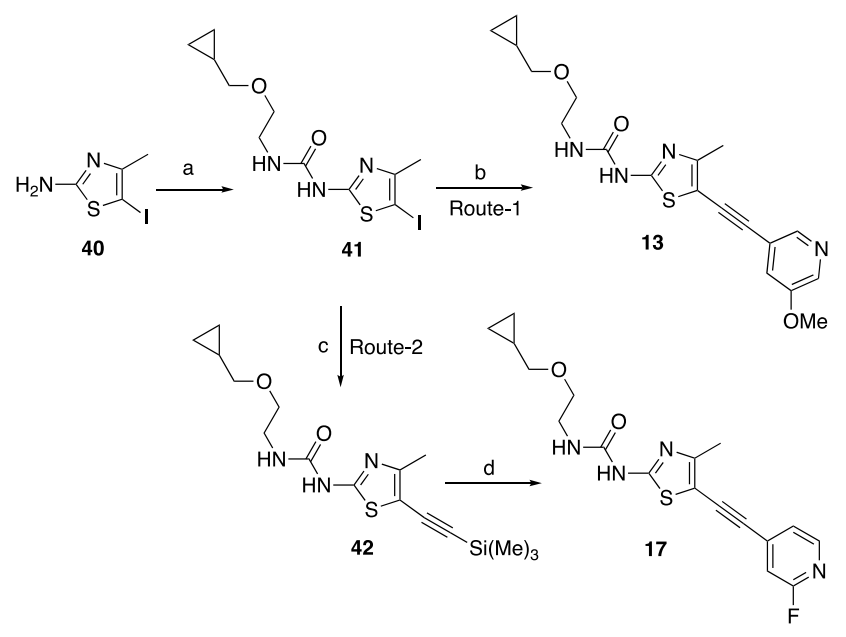

1-(Cyclopropylmethyl)-3-(5-iodo-4-methylthiazol-2-yl)urea (41) 
To a stirred solution of iodo-4-methyl-thiazol-2-amine $\mathbf{4 0}$ (3.46 g, $14.41 \mathrm{mmol})$ in DCM (72 mL) was added CDI (2.57 g, $15.85 \mathrm{mmol}$ ) and the solution was heated at $60{ }^{\circ} \mathrm{C}$ for $2 \mathrm{~h}$. The reaction mixture was cooled and 2(cyclopropylmethoxy) ethanamine $(2.5 \mathrm{~g}, 21.62 \mathrm{mmol})$. The solution was stirred at $\mathrm{RT}$ for $2 \mathrm{~h}$. The reaction mixture was washed with water, the organic layer was dried over $\mathrm{Na}_{2} \mathrm{SO}_{4}$. The solvent was removed under reduced pressure and the crude product was purified by ISCO eluting with ethyl acetate /hexanes to afford compound 41 (2.5 g, 45\%). ${ }^{1}$ HNMR (DMSO-d6): $10.56(\mathrm{~s}, 1 \mathrm{H}), 6.55$ - $6.65(\mathrm{~m}, 1 \mathrm{H}), 3.48$ - $3.44(\mathrm{~m}, 2 \mathrm{H}), 3.34$ - $3.25(\mathrm{~m}, 4 \mathrm{H}), 2.42(\mathrm{~s}, 3 \mathrm{H})$, $1.00-0.97(\mathrm{~m}, 1 \mathrm{H}), 0.47-0.43(\mathrm{~m}, 2 \mathrm{H}), 0.17-0.20(\mathrm{~m}, 2 \mathrm{H})$. mass spectrum (ESI) m/z [M $+\mathrm{H}]^{+} 282.5\left(\mathrm{C}_{11} \mathrm{H}_{16}\left[\mathrm{~N}_{3} \mathrm{O}_{2} \mathrm{~S}\right)\right.$ requires 282.0 .

\section{1-(Cyclopropylmethyl)-3-(5-ethynyl-4-methylthiazol-2-yl)urea (42)}

A solution of 41 (740 mg, $1.941 \mathrm{mmol})$, ethynyl(trimethyl)silane $(591.0 \mathrm{mg}, 850.4 \mu \mathrm{L}$, $6.017 \mathrm{mmol}), \mathrm{Et}_{3} \mathrm{~N}(0.406 \mathrm{~mL})$ in THF $(1 \mathrm{~mL})$ was purged with $\mathrm{N}_{2}(5 \mathrm{~min}) \mathrm{Pd}\left(\mathrm{PPh}_{3}\right)_{4}$ and (224 mg, $0.19 \mathrm{mmol}$ ), CuI (74 mg, $0.39 \mathrm{mmol}$ were added. The solution was warmed to 65 ${ }^{\circ} \mathrm{C}$ and TBAF in THF $(0.2 \mathrm{~mL})$ ) dropwise. The solution was stirred at $65^{\circ} \mathrm{C}$ for $1 \mathrm{~h}$ and the solvent was evaporated under reduced pressure. The crude product was purified by ISCO eluting with (EtOAc/hexanes 1:1) to afford compound 1-(cyclopropylmethyl)-3-(4methyl-5-((trimethylsilyl)ethynyl)thiazol-2-yl)urea (396 mg, 58\%) Mass spectrum (ESI) $\mathrm{m} / \mathrm{z}[\mathrm{M}+\mathrm{H}]^{+}=352.4$. mass spectrum (ESI) $\mathrm{m} / \mathrm{z}[\mathrm{M}+\mathrm{H}]^{+} 352.4\left(\mathrm{C}_{16} \mathrm{H}_{25} \mathrm{~N}_{3} \mathrm{O}_{2} \mathrm{SSi}\right)$ requires 352.2 .

1-(2-(Cyclopropylmethoxy)ethyl)-3-(5-((5-methoxypyridin-3-yl)ethynyl)-4methylthiazol-2-yl)urea (13) 


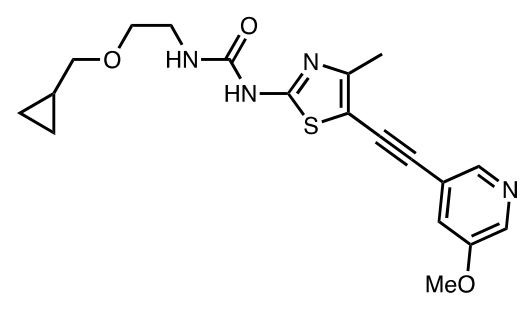

A solution of 3-ethynyl-5-methoxypyridine (26.20 mg, $0.197 \mathrm{mmol}), 42(50 \mathrm{mg}, 0.13$ $\mathrm{mmol}), \mathrm{Et}_{3} \mathrm{~N}(0.055 \mathrm{~mL})$ in THF $(3 \mathrm{~mL})$ was purged with $\mathrm{N}_{2}(5 \mathrm{~min})$ and $\mathrm{Pd}\left(\mathrm{PPh}_{4}\right)_{3}(23$ $\mathrm{mg}, 0.02 \mathrm{mmol})$ and $\mathrm{CuI}(8 \mathrm{mg}, 0.32 \mathrm{mmol})$ were added. The solution was stirred at $65{ }^{\circ} \mathrm{C}$ for $1 \mathrm{~h}$ and the solvent was evaporated under reduced pressure. The crude product was purified by reversed-phase chromatography (Column: C18. Gradient: 0-100 \% $\mathrm{MeCN}$ in water with $0.1 \% \mathrm{HCl}$ ) to afford compound $\mathbf{1 3 . H C l}(23 \mathrm{mg}, 41.4 \%)$. ${ }^{1} \mathrm{HNMR}$ (DMSO- $d_{6}$ ): $\delta 10.79$ (brs, 1H), 8.40 (brs, 2H), 7.60 (s, 1H), 6.76 (s, 1H), 3.87 (s, 3H), 3.48 - 3.45 (m, $2 \mathrm{H}), 3.32$ - $3.24(\mathrm{~m}, 4 \mathrm{H}), 2.36(\mathrm{~s}, 3 \mathrm{H}), 1.00(\mathrm{~m}, 1 \mathrm{H}), 0.48$ - $0.45(\mathrm{~m}, 2 \mathrm{H}), 0.19-0.17(\mathrm{~m}$, $2 \mathrm{H})$. HRMS: $\mathrm{m} / \mathrm{z}$ calcd for $\mathrm{C}_{19} \mathrm{H}_{22} \mathrm{~N}_{4} \mathrm{O}_{3} \mathrm{~S}\left[\mathrm{M}^{+}+1\right] 387.1485$; found 387.1485 .

\section{1-(2-(Cyclopropylmethoxy)ethyl)-3-(5-((5,6-dimethoxypyridin-3-yl)ethynyl)-4-} methylthiazol-2-yl)urea (14)

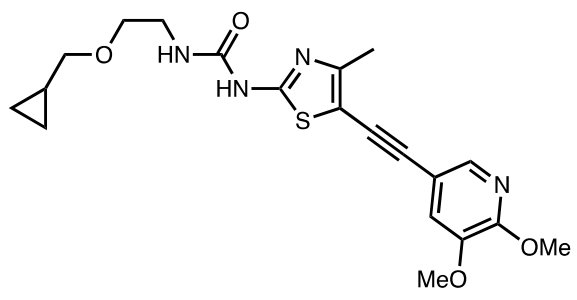

Compound 14 was synthesized in a manner similar to compound 13 using 41 and 2-methoxy-4-((trimethylsilyl)ethynyl)pyridine to afford 14. 0.5 methane sulfonic acid salt (21.4 mg, 40\%). ${ }^{1} \mathrm{HNMR}\left(300 \mathrm{MHz}, \mathrm{DMSO}-d_{6}\right) \delta 10.67(\mathrm{~s}, 1 \mathrm{H})$, $7.89(\mathrm{~d}, J=1.8 \mathrm{~Hz}, 1 \mathrm{H}), 7.40$ (d, $J=1.8 \mathrm{~Hz}, 1 \mathrm{H}), 6.67-6.65(\mathrm{~m}, 1 \mathrm{H}), 3.89(\mathrm{~s}, 3 \mathrm{H}), 3.82$ (s, 3H), $3.46(\mathrm{t}, J=5.5 \mathrm{~Hz}, 2 \mathrm{H}), 3.34-3.23(\mathrm{~m}, 4 \mathrm{H}), 2.33(\mathrm{~s}, 3 \mathrm{H}), 1.10-0.84(\mathrm{~m}, 1 \mathrm{H}), 0.57$ - $0.36(\mathrm{~m}, 2 \mathrm{H}), 0.30-0.09(\mathrm{~m}, 2 \mathrm{H})$. HRMS: $\mathrm{m} / \mathrm{z}$ calcd for $\mathrm{C}_{20} \mathrm{H}_{24} \mathrm{~N}_{4} \mathrm{O}_{4} \mathrm{~S}\left[\mathrm{M}^{+}+1\right] 417.1590$ found 417.1591 . 
1-(2-(Cyclopropylmethoxy)ethyl)-3-(5-((2-methoxypyridin-4-yl)ethynyl)-4methylthiazol-2-yl)urea (15)

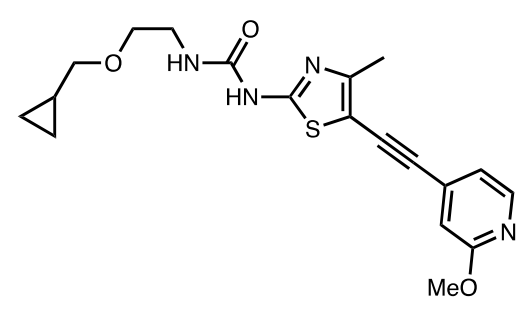

Compound 15 was synthesized in a manner similar to compound 13 using 41 and 2-methoxy-4-((trimethylsilyl)ethynyl)pyridine to afford 15.HCl (25 mg, 52\%). ${ }^{1} \mathrm{H}$ NMR (300 MHz, DMSO- $\left.d_{6}\right) \delta 10.79(\mathrm{~s}, 1 \mathrm{H}), 8.17(\mathrm{~d}, 1 \mathrm{H}), 7.05(\mathrm{dd}, 1 \mathrm{H})$, $6.91(\mathrm{~s}, 1 \mathrm{H}), 6.70(\mathrm{t}, 1 \mathrm{H}), 3.86(\mathrm{~s}, 3 \mathrm{H}), 3.46(\mathrm{t}, 2 \mathrm{H}), 3.29(\mathrm{~m}, 4 \mathrm{H}), 2.35(\mathrm{~s}, 3 \mathrm{H}), 0.99(\mathrm{~m}$, $1 \mathrm{H}), 0.46(\mathrm{~m}, 2 \mathrm{H}), 0.18(\mathrm{~m}, 2 \mathrm{H})$. HRMS: m/z calcd for $\mathrm{C}_{19} \mathrm{H}_{22} \mathrm{~N}_{4} \mathrm{O}_{3} \mathrm{~S}\left[\mathrm{M}^{+}+1\right] 387.1485$; found 387.1484 .

\section{(2-(Cyclopropylmethoxy)ethyl)-3-(5-((6-methoxypyridin-2-yl)ethynyl)-4-} methylthiazol-2-yl)urea (16)

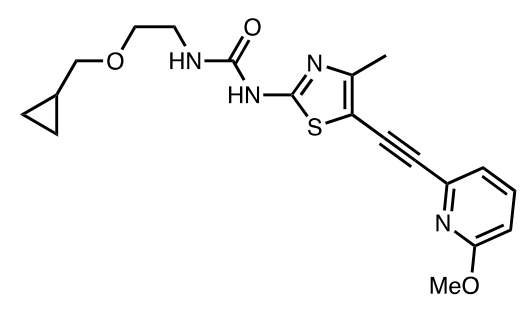

Compound 16 was synthesized in a manner similar to compound 17 using 42 and 2-bromo-6-methoxypyridine to afford 16.HCl (16 mg, 27\%). ${ }^{1} \mathrm{HNMR}\left(\mathrm{DMSO}-d_{6}\right): \delta 10.81$ (brs, $\left.1 \mathrm{H}\right), 7.72(\mathrm{dd}, J=8.3,7.4 \mathrm{~Hz}, 1 \mathrm{H}), 7.21(\mathrm{~d}, J=7.2 \mathrm{~Hz}$, $1 \mathrm{H}), 6.83(\mathrm{~d}, J=8.3 \mathrm{~Hz}, 1 \mathrm{H}), 6.67-6.66(\mathrm{~m}, 1 \mathrm{H}), 3.87(\mathrm{~s}, 3 \mathrm{H}), 3.46(\mathrm{t}, J=5.5 \mathrm{~Hz}, 2 \mathrm{H})$, $3.37-3.28(\mathrm{~m}, 2 \mathrm{H}), 3.26(\mathrm{~d}, J=6.8 \mathrm{~Hz}, 2 \mathrm{H}), 2.35(\mathrm{~s}, 3 \mathrm{H}), 1.10-0.90(\mathrm{~m}, 1 \mathrm{H}), 0.65-0.37$ $(\mathrm{m}, 2 \mathrm{H}), 0.25-0.08(\mathrm{~m}, 2 \mathrm{H})$. HRMS: m/z calcd for $\mathrm{C}_{19} \mathrm{H}_{22} \mathrm{~N}_{4} \mathrm{O}_{3} \mathrm{~S}\left[\mathrm{M}^{+}+1\right] 387.1484$; found 387.1485 . 


\section{1-(2-(Cyclopropylmethoxy)ethyl)-3-(5-((2-fluoropyridin-4-yl)ethynyl)-4- methylthiazol-2-yl)urea (17)}

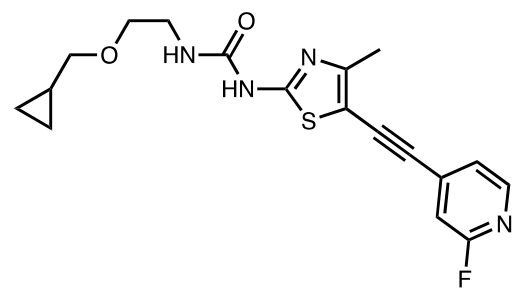

To a solution of compound 42 (50 $\mathrm{mg}, 0.142 \mathrm{mmol}), 2$-fluoro-4-iodo-pyridine (32 $\mathrm{mg}$, $0.143 \mathrm{mmol})$ and $\mathrm{Et}_{3} \mathrm{~N}(0.025 \mathrm{~mL})$ in THF $(1 \mathrm{~mL})$ were added $\mathrm{Pd}\left(\mathrm{PPh}_{3}\right)_{4}(16 \mathrm{mg}, 0.016$ $\mathrm{mmol}$ ) and $\mathrm{CuI}(6 \mathrm{mg}, 0.03 \mathrm{mmol})$ were added and purged with $\mathrm{N}_{2}$. The solution was heated at $65^{\circ} \mathrm{C}$ and a solution of TBAF ( $1 \mathrm{M}$ in THF, $\left.0.3 \mathrm{~mL}\right)$ was added dropwise. The solution was stirred at $65^{\circ} \mathrm{C}$ for $1 \mathrm{~h}$. The solvent was evaporated under reduced pressure. The crude product was purified by ISCO eluting with EtOAc/hexanes $(1: 1)$ and the pure product was dissolved in $\mathrm{CH}_{3} \mathrm{CN}(0.2 \mathrm{~mL})$ and $2 \mathrm{~N} \mathrm{HCl}(0.1 \mathrm{~mL})$ was added. The mixture was lyophilized to afford to afford $17(29.4 \mathrm{mg}, 50.3 \%)$ as yellow solid. ${ }^{1} \mathrm{H}$ NMR (300 MHz, DMSO- $\left.d_{6}\right) \delta 10.90(\mathrm{~m}, 1 \mathrm{H}), 8.25(\mathrm{~d}, J=5.2 \mathrm{~Hz}, 1 \mathrm{H}), 7.44(\mathrm{~d}, J=5.2 \mathrm{~Hz}, 1 \mathrm{H}), 7.33(\mathrm{~s}, 1 \mathrm{H})$, $6.75(\mathrm{~m}, 1 \mathrm{H}), 3.46(\mathrm{t}, J=5.5 \mathrm{~Hz}, 2 \mathrm{H}), 3.32-3.25(\mathrm{~m}, 4 \mathrm{H}), 2.34(\mathrm{~s}, 3 \mathrm{H}), 1.13-0.86(\mathrm{~m}$, $1 \mathrm{H}), 0.55-0.40(\mathrm{~m}, 2 \mathrm{H}), 0.19-0.19(\mathrm{~m}, 2 \mathrm{H})$. HRMS: $\mathrm{m} / \mathrm{z}$ calcd for $\mathrm{C}_{18} \mathrm{H}_{19} \mathrm{FN}_{4} \mathrm{O}_{2} \mathrm{~S}\left[\mathrm{M}^{+}\right.$ $+1] 375.1289$; found 375.1292 .

\section{1-(5-((2-Chloropyridin-4-yl)ethynyl)-4-methylthiazol-2-yl)-3-(2}

(cyclopropylmethoxy)ethyl)urea (18)

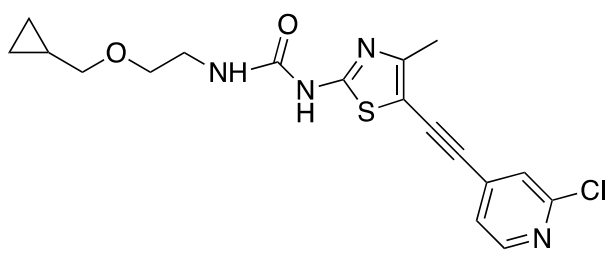

Compound 18 was synthesized in a manner similar to compound 17 using 42 and 2-fluoro4-iodo-pyridine to afford 18.HCl (20 mg, 33\%) ${ }^{1} \mathrm{HNMR}\left(\mathrm{DMSO}-d_{6}\right): 10.77(\mathrm{~s}, 1 \mathrm{H}), 9.01$ $(\mathrm{s}, 1 \mathrm{H}), 8.93(\mathrm{~s}, 1 \mathrm{H}), 8.42(\mathrm{~s}, 1 \mathrm{H}), 6.68(\mathrm{t}, 1 \mathrm{H}), 3.46(\mathrm{~m}, 2 \mathrm{H}), 3.27(\mathrm{~m}, 4 \mathrm{H}), 2.38(\mathrm{~s}, 3 \mathrm{H}), 1.00$ $(\mathrm{m}, 1 \mathrm{H}), 0.47(\mathrm{~m}, 2 \mathrm{H}), 0.19(\mathrm{~m}, 2 \mathrm{H}) . \mathrm{HRMS}: \mathrm{m} / \mathrm{z}$ calcd for $\mathrm{C}_{18} \mathrm{H}_{19} \mathrm{ClN}_{4} \mathrm{O}_{2} \mathrm{~S}\left[\mathrm{M}^{+}+1\right]$ 
391.0990; found 391.0992.

1-(2-(Cyclopropylmethoxy)ethyl)-3-(4-methyl-5-((5-(trifluoromethyl)pyridin-3yl)ethynyl)thiazol-2-yl)urea (19)

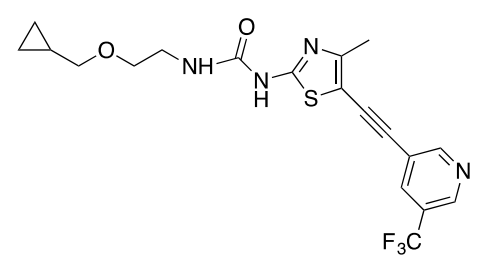

Compound 19 was synthesized in a manner similar to compound 17 using 42 and 3-iodo5-(trifluoromethyl)pyridine to afford 19.HCl (30 mg, 50\%). ${ }^{1} \mathrm{HNMR}$ (DMSO- $d_{6}$ ): $\delta 10.77$ (s, 1H), 9.01(s, 1H), $8.93(\mathrm{~s}, 1 \mathrm{H}), 8.42(\mathrm{~s}, 1 \mathrm{H}), 6.70$ - $6.68(\mathrm{~m}, 1 \mathrm{H}), 3.47(\mathrm{~m}, 2 \mathrm{H}), 3.27(\mathrm{~m}$, $4 \mathrm{H}), 2.40(\mathrm{~s}, 3 \mathrm{H}), 1.01(\mathrm{~m}, 1 \mathrm{H}), 0.52-0.43(\mathrm{~m}, 2 \mathrm{H}), 0.19(\mathrm{~m}, 2 \mathrm{H})$. HRMS: $\mathrm{m} / \mathrm{z}$ calcd for $\mathrm{C}_{19} \mathrm{H}_{19} \mathrm{~F}_{3} \mathrm{~N}_{4} \mathrm{O}_{2} \mathrm{~S}\left[\mathrm{M}^{+}+1\right] 425.1260$; found 425.1253.

1-(2-(Cyclopropylmethoxy)ethyl)-3-(5-((5,6-dimethoxypyrazin-2-yl)ethynyl)-4methylthiazol-2-yl)urea (20)

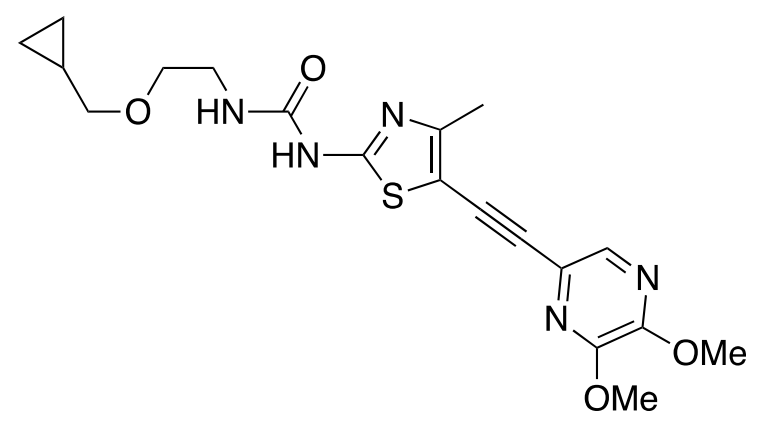

Compound 20 was synthesized in a manner similar to compound 17 using 42 and 5-bromo2,3-dimethoxypyrazine to afford $20 \mathrm{HCl}$. (13 mg, 20\%). ${ }^{1} \mathrm{HNMR}$ (DMSO- $d_{6}$ ): $\delta 10.73$ (s, $1 \mathrm{H}), 7.96(\mathrm{~s}, 1 \mathrm{H}), 6.75-6.65(\mathrm{~m}, 1 \mathrm{H}), 3.94(\mathrm{~s}, 3 \mathrm{H}), 3.93(\mathrm{~s}, 3 \mathrm{H}), 3.46(\mathrm{t}, J=5.5 \mathrm{~Hz}, 2 \mathrm{H})$, 3.39 - 3.29 (m, 2H), 3.26 (d, J=6.8 Hz, 2H), 2.33 (s, 3H), 0.97 (m, 1H), 0.54 - 0.37 (m, $2 \mathrm{H}), 0.24-0.10(\mathrm{~m}, 2 \mathrm{H})$. HRMS: $\mathrm{m} / \mathrm{z}$ calcd for $\mathrm{C}_{19} \mathrm{H}_{23} \mathrm{~F}_{3} \mathrm{~N}_{5} \mathrm{O}_{4} \mathrm{~S}\left[\mathrm{M}^{+}+1\right] 418.1543$; found 418.1540 .

1-(2-(Cyclopropylmethoxy)ethyl)-3-(4-methyl-5-(quinolin-3-ylethynyl)thiazol-2- 


\section{yl)urea (21)}

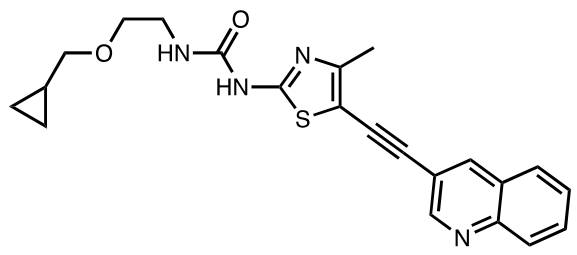

Compound 21 was synthesized in a manner similar to compound 13 using 42 and 3bromoquinoline to afford 21 (09 mg, 15.5\%). ${ }^{1} \mathrm{H}$ NMR (300 MHz, DMSO- $\left.d_{6}\right) \delta 10.87$ (m, $1 \mathrm{H}), 9.05(\mathrm{~d}, J=2.0 \mathrm{~Hz}, 1 \mathrm{H}), 8.69$ (d, $J=1.8 \mathrm{~Hz}, 1 \mathrm{H}), 8.06(\mathrm{dd}, J=12.2,8.1 \mathrm{~Hz}, 2 \mathrm{H})$, $7.85(\mathrm{t}, J=7.1 \mathrm{~Hz}, 1 \mathrm{H}), 7.71(\mathrm{t}, J=7.4 \mathrm{~Hz}, 1 \mathrm{H}), 6.83(\mathrm{t}, J=5.4 \mathrm{~Hz}, 1 \mathrm{H}), 3.47(\mathrm{t}, J=5.5$ $\mathrm{Hz}, 2 \mathrm{H}), 3.42-3.25(\mathrm{~m}, 4 \mathrm{H}), 2.41(\mathrm{~s}, 3 \mathrm{H}), 1.12$ - $0.85(\mathrm{~m}, 1 \mathrm{H}), 0.58$ - $0.35(\mathrm{~m}, 2 \mathrm{H}), 0.33$ 0.05 (m, 2H). HRMS: m/z calcd for $\mathrm{C}_{22} \mathrm{H}_{22} \mathrm{~N}_{4} \mathrm{O}_{2} \mathrm{~S}\left[\mathrm{M}^{+}+1\right]$ 407.1536; found 407.153.

\section{1-(2-(Cyclopropylmethoxy)ethyl)-3-(4-methyl-5-(quinolin-4-ylethynyl)thiazol-2-}

\section{yl)urea (22)}

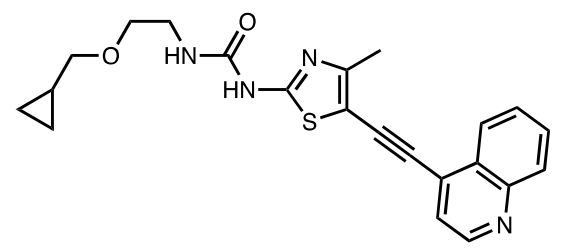

Compound 22 was synthesized in a manner similar to compound 17 using 42 and 4iodoquinoline to afford $22(09 \mathrm{mg}, 15.5 \%),{ }^{1} \mathrm{H}$ NMR $\left(300 \mathrm{MHz}, \mathrm{DMSO}-d_{6}\right) \delta 11.12(\mathrm{~s}, 1 \mathrm{H})$, $9.08(\mathrm{~d}, J=5.2 \mathrm{~Hz}, 1 \mathrm{H}), 8.37(\mathrm{~d}, J=8.2 \mathrm{~Hz}, 1 \mathrm{H}), 8.24(\mathrm{~d}, J=8.4 \mathrm{~Hz}, 1 \mathrm{H}), 8.04(\mathrm{t}, J=7.1$ $\mathrm{Hz}, 1 \mathrm{H}), 7.96(\mathrm{~d}, J=5.1 \mathrm{~Hz}, 1 \mathrm{H}), 7.95-7.85(\mathrm{~m}, 1 \mathrm{H}), 6.92(\mathrm{t}, J=5.4 \mathrm{~Hz}, 1 \mathrm{H}), 3.48$ (t, $J=$ $5.5 \mathrm{~Hz}, 2 \mathrm{H}), 3.35-3.26(\mathrm{~m}, 4 \mathrm{H}), 2.53(\mathrm{~s}, 3 \mathrm{H}), 1.08$ - $0.91(\mathrm{~m}, 1 \mathrm{H}), 0.52$ - $0.37(\mathrm{~m}, 2 \mathrm{H}), 0.25$ - $0.12(\mathrm{~m}, 2 \mathrm{H})$. mass spectrum $(\mathrm{ESI}) \mathrm{m} / \mathrm{z}[\mathrm{M}+\mathrm{H}]^{+} 407.1\left(\mathrm{C}_{22} \mathrm{H}_{22} \mathrm{~N}_{4} \mathrm{O}_{2} \mathrm{~S}\right)$ requires 407.5.

\section{1-(2-(Cyclopropylmethoxy)ethyl)-3-(5-(imidazo[1,2-a]pyridin-6-ylethynyl)-4-} methylthiazol-2-yl)urea (23)

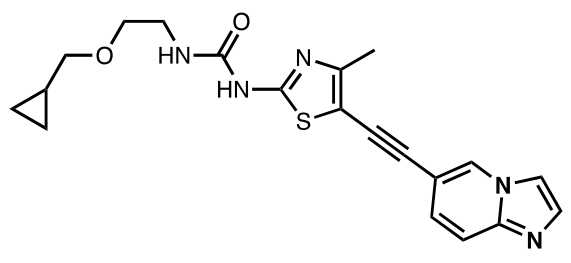


Compound 23 was synthesized in a manner similar to compound 17 using 42 and 6iodoimidazo[1,2-a]pyridine to afford 23.HCl (12.3mg, 20\%). ${ }^{1} \mathrm{H}$ NMR (300 MHz, DMSO$\left.d_{6}\right) \delta 10.86(\mathrm{~s}, 1 \mathrm{H}), 9.23(\mathrm{~s}, 1 \mathrm{H}), 8.28-8.25(\mathrm{~m}, 2 \mathrm{H}), 7.99(\mathrm{~s}, 2 \mathrm{H}), 6.81(\mathrm{t}, J=5.4 \mathrm{~Hz}, 1 \mathrm{H})$, 3.46 - $3.11(\mathrm{~m}, 6 \mathrm{H}), 2.32(\mathrm{~s}, 3 \mathrm{H}), 1.01-0.96(\mathrm{~m}, 1 \mathrm{H}), 0.58$ - $0.30(\mathrm{~m}, 2 \mathrm{H}), 0.29$ - $0.11(\mathrm{~m}$, 2H). HRMS: $\mathrm{m} / \mathrm{z}$ calcd for $\mathrm{C}_{20} \mathrm{H}_{21} \mathrm{~N}_{5} \mathrm{O}_{2} \mathrm{~S}\left[\mathrm{M}^{+}+1\right]$ 396.1489; found 396.1487 .

1-(5-((1H-pyrrolo[2,3-b]pyridin-5-yl)ethynyl)-4-methylthiazol-2-yl)-3-(2(cyclopropylmethoxy)ethyl)urea (24).

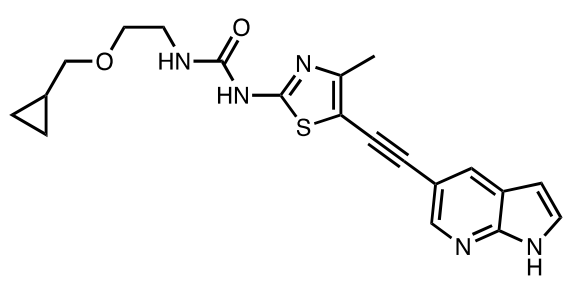

Compound 24 was synthesized in a manner similar to compound 17 using $\mathbf{4 2}$ and 5-iodo$1 H$-pyrrolo[2,3-b]pyridine to afford 24.HCl (16 mg, 26\%). ${ }^{1} \mathrm{H}$ NMR (300 MHz, DMSO$\left.d_{6}\right) \delta 11.94(\mathrm{~s}, 1 \mathrm{H}), 10.5$ (brs, 1H), 8.17 (s, 1H), 7.55 (d, $\left.J=3.3 \mathrm{~Hz}, 1 \mathrm{H}\right), 6.74(\mathrm{~s}, 1 \mathrm{H}), 6.52$ (s, 1H), $3.46(\mathrm{t}, J=5.5 \mathrm{~Hz}, 2 \mathrm{H}), 3.39-3.15(\mathrm{~m}, 5 \mathrm{H}), 2.31(\mathrm{~s}, 3 \mathrm{H}), 0.97(\mathrm{~m}, 1 \mathrm{H}), 0.58-0.36$ (m, $2 \mathrm{H}), 0.29-0.13(\mathrm{~m}, 2 \mathrm{H})$. HRMS: $\mathrm{m} / \mathrm{z}$ calcd for $\mathrm{C}_{20} \mathrm{H}_{21} \mathrm{~N}_{5} \mathrm{O}_{2} \mathrm{~S}\left[\mathrm{M}^{+}+1\right] 396.1491$; found 396.1489 .

1-(5-((1,8-Naphthyridin-3-yl)ethynyl)-4-methylthiazol-2-yl)-3-(2(cyclopropylmethoxy)ethyl)urea (25)

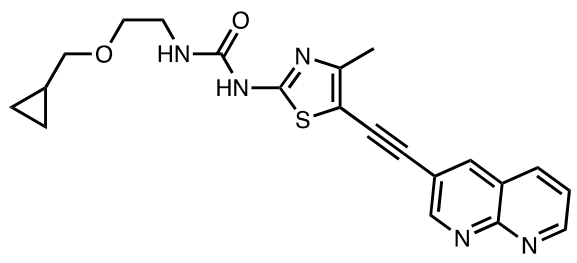

Compound 25 was synthesized in a manner similar to compound 13 using 42 and 3-bromo1,8-naphthyridine to afford 25. HCl (5.5 mg, 08.6\%). ${ }^{1} \mathrm{H}$ MR (300 MHz, DMSO- $\left.d_{6}\right) \delta 10.83$ (m, 1H), 9.25-9.18 (brm, 2H), 8.72 (s, 1H), 8.52 (d, $J=8.2 \mathrm{~Hz}, 1 \mathrm{H}), 7.76(\mathrm{~m}, 1 \mathrm{H}), 6.78$ (t, 
$J=5.3 \mathrm{~Hz}, 1 \mathrm{H}), 3.47(\mathrm{t}, J=5.5 \mathrm{~Hz}, 2 \mathrm{H}), 3.48-3.25(\mathrm{~m}, 4 \mathrm{H}), 2.41(\mathrm{~s}, 3 \mathrm{H}), 1.12-0.90(\mathrm{~m}$, $1 \mathrm{H}), 0.55-0.39(\mathrm{~m}, 2 \mathrm{H}), 0.19-0.16(\mathrm{~m}, 2 \mathrm{H})$. HRMS: $\mathrm{m} / \mathrm{z}$ calcd for $\mathrm{C}_{21} \mathrm{H}_{21} \mathrm{~N}_{5} \mathrm{O}_{2} \mathrm{~S}\left[\mathrm{M}^{+}+1\right]$ 408.1489; found 408.1493.

\section{1-(2-(Cyclopropylmethoxy)ethyl)-3-(4-methyl-5-(pyrido[2,3-b]pyrazin-7-} ylethynyl)thiazol-2-yl)urea (26)

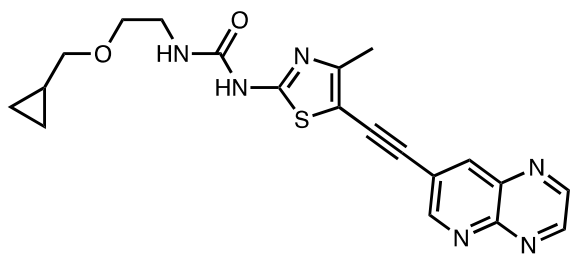

Compound 26 was synthesized in a manner similar to compound 17 using 42 and 7bromopyrido[2,3-b]pyrazine afford 26.HCI (11 mg, 19\%). ${ }^{1} \mathrm{H}$ NMR (300 MHz, DMSO- $\left.d_{6}\right)$ $\delta 10.74$ (brs, 1H), 9.05-8.99 (m, 1H), 8.52 (s, 1H), 7.79 - $7.25(\mathrm{~m}, 2 \mathrm{H}), 6.64(\mathrm{~s}, 1 \mathrm{H}), 3.34$ - $3.25(\mathrm{~m}, 2 \mathrm{H}), 3.16-3.07(\mathrm{~m}, 4 \mathrm{H}), 2.25(\mathrm{~s}, 3 \mathrm{H}), 0.94$ - $0.66(\mathrm{~m}, 1 \mathrm{H}), 0.39-0.23(\mathrm{~m}, 2 \mathrm{H})$, $0.08-0.02(\mathrm{~m}, 2 \mathrm{H})$; Mass spectrum (ESI) $\mathrm{m} / \mathrm{z}[\mathrm{M}+\mathrm{H}]^{+}=410.4$. HRMS: $\mathrm{m} / \mathrm{z}$ calcd for $\mathrm{C}_{20} \mathrm{H}_{20} \mathrm{~N}_{6} \mathrm{O}_{2} \mathrm{~S}\left[\mathrm{M}^{+}+1\right] 409.1441$; found 409.1441

\section{(R)-1-(1-(Cyclopropylmethoxy)propan-2-yl)-3-(4-methyl-5-(pyridin-4-} ylethynyl)thiazol-2-yl)urea (27)

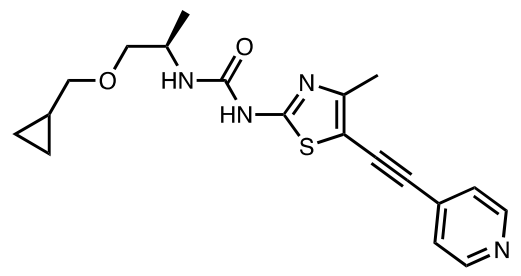

Compound 27 was synthesized in a manner similar to compound 6 using 45 and $(R)-1$ (cyclopropylmethoxy)propan-2-amine to afford 27.HCl (23 mg, 31.6\%). ${ }^{1} \mathrm{H}$ NMR (300 $\left.\mathrm{MHz}, \mathrm{CD}_{3} \mathrm{OD}\right) \delta 8.74(\mathrm{~d}, J=9.0 \mathrm{~Hz}, 2 \mathrm{H}), 8.04(\mathrm{~d}, J=6.0 \mathrm{~Hz}, 2 \mathrm{H}), 4.01-3.97(\mathrm{~m}, 1 \mathrm{H})$, 3.49-3.45 (m, 2H), 3.33- $3.30(\mathrm{~m}, 2 \mathrm{H}), 2.49$ (s, 3H), 1.22 (d, $J=6.0 \mathrm{~Hz}, 3 \mathrm{H}), 1.06-1.04$ (m, $1 \mathrm{H}), 0.53-0.49(\mathrm{~m}, 2 \mathrm{H}), 0.20-0.23(\mathrm{~m}, 2 \mathrm{H})$. HRMS: $\mathrm{m} / \mathrm{z}$ calcd for $\mathrm{C}_{19} \mathrm{H}_{22} \mathrm{~N}_{4} \mathrm{O}_{2} \mathrm{~S}\left[\mathrm{M}^{+}+1\right]$ 371.1538 ; found 371.1536 
(S)-1-(1-(Cyclopropylmethoxy)propan-2-yl)-3-(4-methyl-5-(pyridin-4ylethynyl)thiazol-2-yl)urea (28)

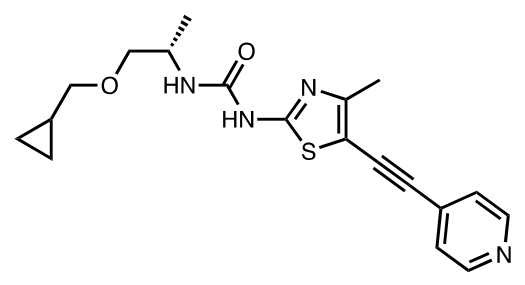

Compound 28 was synthesized in a manner similar to compound 6 using 45 and $(S)$-1(cyclopropylmethoxy)propan-2-amine to afford 27.HCl (27 mg, 39\%). ${ }^{1} \mathrm{H}$ NMR (300 $\left.\mathrm{MHz}, \mathrm{CD}_{3} \mathrm{OD}\right) \delta 8.74(\mathrm{~s}, 2 \mathrm{H}), 8.04(\mathrm{~s}, 2 \mathrm{H}), 4.01-3.97(\mathrm{~m}, 1 \mathrm{H}), 3.49-3.45(\mathrm{~m}, 2 \mathrm{H}), 3.33-$ $3.30(\mathrm{~m}, 2 \mathrm{H}), 2.49$ (s, 3H), $1.22(\mathrm{~d}, J=6.0 \mathrm{~Hz}, 3 \mathrm{H}), 1.06-1.04(\mathrm{~m}, 1 \mathrm{H}), 0.53-0.49(\mathrm{~m}, 2 \mathrm{H})$, 0.20-0.23 (m, 2H). HRMS: m/z calcd for $\mathrm{C}_{19} \mathrm{H}_{22} \mathrm{~N}_{4} \mathrm{O}_{2} \mathrm{~S}\left[\mathrm{M}^{+}+1\right] 371.1536$; found 371.1542.

\section{R)-1-(2-(Cyclopropylmethoxy)propyl)-3-(4-methyl-5-(pyridin-4-ylethynyl)thiazol-2-} yl)urea (29)

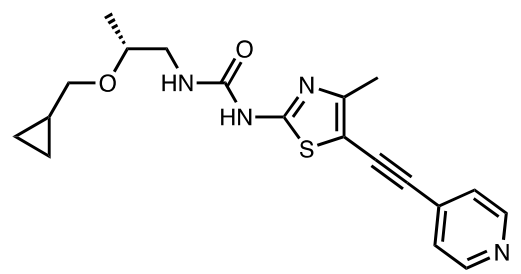

Compound 29 was synthesized in a manner similar to compound 6 using 45 and $(R)$-2(cyclopropylmethoxy)propan-1-amine to afford 29.HCl (2.5 mg, 04\%). ${ }^{1} \mathrm{H}$ NMR (300 $\left.\mathrm{MHz}, \mathrm{CD}_{3} \mathrm{OD}\right) \delta 8.75(\mathrm{~d}, J=9 \mathrm{~Hz}, 2 \mathrm{H}), 8.03(\mathrm{~d}, J=9 \mathrm{~Hz}, 2 \mathrm{H}), 3.66-3.61(\mathrm{~m}, 1 \mathrm{H}), 3.42-$ $3.31(\mathrm{~m}, 3 \mathrm{H}), 3.21-3.15(\mathrm{~m}, 1 \mathrm{H}), 2.49(\mathrm{~s}, 3 \mathrm{H}), 1.16(\mathrm{~d}, J=6.0 \mathrm{~Hz}, 3 \mathrm{H}), 1.07-0.98(\mathrm{~m}, 1 \mathrm{H})$, 0.50-0.48 (m, 2H), 0.22-0.19 (m, 2H). HRMS: m/z calcd for $\mathrm{C}_{19} \mathrm{H}_{22} \mathrm{~N}_{4} \mathrm{O}_{2} \mathrm{~S}\left[\mathrm{M}^{+}+1\right]$ 371.1536; found 371.1536 .

(S)-1-(2-(Cyclopropylmethoxy)propyl)-3-(4-methyl-5-(pyridin-4-ylethynyl)thiazol-2yl)urea (30) 


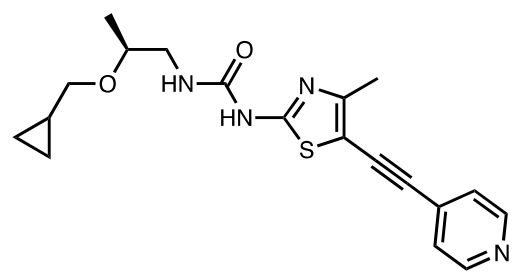

Compound 30 was synthesized in a manner similar to compound 6 using 45 and (S)-2(cyclopropylmethoxy)propan-1-amine to afford 30.HCl (31 mg, 46\%). ${ }^{1} \mathrm{H}$ NMR (300 $\left.\mathrm{MHz}, \mathrm{CD}_{3} \mathrm{OD}\right) \delta 8.75(\mathrm{~d}, J=9 \mathrm{~Hz}, 2 \mathrm{H}), 8.03(\mathrm{~d}, J=9 \mathrm{~Hz}, 2 \mathrm{H}), 3.66-3.61(\mathrm{~m}, 1 \mathrm{H}), 3.42-$ $3.31(\mathrm{~m}, 3 \mathrm{H}), 3.21-3.15(\mathrm{~m}, 1 \mathrm{H}), 2.49(\mathrm{~s}, 3 \mathrm{H}), 1.16(\mathrm{~d}, J=6.0 \mathrm{~Hz}, 3 \mathrm{H}), 1.07-0.98(\mathrm{~m}, 1 \mathrm{H})$, 0.50-0.48 (m, $2 \mathrm{H}), 0.22-0.19(\mathrm{~m}, 2 \mathrm{H})$. mass spectrum (ESI) $\mathrm{m} / \mathrm{z}[\mathrm{M}+\mathrm{H}]^{+}=371.4$. HRMS: $\mathrm{m} / \mathrm{z}$ calcd for $\mathrm{C}_{19} \mathrm{H}_{22} \mathrm{~N}_{4} \mathrm{O}_{2} \mathrm{~S}\left[\mathrm{M}^{+}+1\right]$ 371.1536; found 371.1534.

\section{1-[(2S)-2-(Cyclopropylmethoxy)propyl]-3-(5-iodo-4-methyl-thiazol-2-yl)urea}

To a stirred solution of $\mathrm{N}^{-}$(5-iodo-4-methyl-thiazol-2-yl)imidazole-1carboxamide (1.39 g, $4.152 \mathrm{mmol}$ ), (2S)-2-(cyclopropylmethoxy)propan-1-amine (590 mg, $4.567 \mathrm{mmol})$ bin THF $(50 \mathrm{~mL})$ was added DIEA $(3.6 \mathrm{~mL})$ and the reaction mixture was stirred at RT for $18 \mathrm{~h}$. The reaction mixture was washed with water, the organic layer was dried over $\mathrm{Na}_{2} \mathrm{SO}_{4}$. The solvent was removed under reduced pressure and the crude product was purified by ISCO eluting with ethyl acetate/hexanes to afford compound 1-[(2S)-2-(cyclopropylmethoxy)propyl]-3-(5-iodo-4-methyl-thiazol-2yl)urea (0.4 g, $24.4 \%$ ); mass spectrum (ESI) $\mathrm{m} / \mathrm{z}[\mathrm{M}+\mathrm{H}]^{+} 396.2\left(\mathrm{C}_{12} \mathrm{H}_{8} \mathrm{~N}_{3} \mathrm{OS}\right)$ requires 396.0

(S)-1-(2-(Cyclopropylmethoxy)propyl)-3-(5-((5-methoxypyridin-3-yl)ethynyl)-4methylthiazol-2-yl)urea (31)

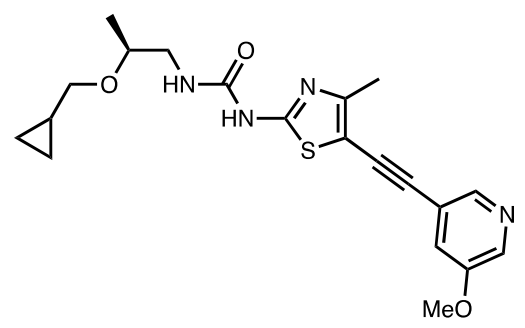

Compound 31 was synthesized in a manner similar to compound 13 using 1-[(2S)-2- 
(cyclopropylmethoxy)propyl]-3-(5-iodo-4-methyl-thiazol-2-yl)urea and 2-methoxy-5((trimethylsilyl)ethynyl)pyridine to afford 31. $\mathrm{HCl}(0.6 .5 \mathrm{mg}, 17.5 \%) .{ }^{1} \mathrm{H}$ NMR $(300 \mathrm{MHz}$, MeOD) $\delta 7.83$-7.35 (m, 3H), 3.91(s, 3H), 3.75 - $3.51(\mathrm{~m}, 1 \mathrm{H}), 3.47$ - $3.25(\mathrm{~m}, 3 \mathrm{H}), 3.17-$ $3.13(\mathrm{~m}, 1 \mathrm{H}), 2.39$ (s, 3H), 1.15 (d, $J=6.2 \mathrm{~Hz}, 3 \mathrm{H}), 1.10-0.92$ (m, 1H), $0.61-0.42$ (m, $2 \mathrm{H}), 0.34-0.13(\mathrm{~m}, 2 \mathrm{H})$. HRMS: $\mathrm{m} / \mathrm{z}$ calcd for $\mathrm{C}_{20} \mathrm{H}_{24} \mathrm{~N}_{4} \mathrm{O}_{3} \mathrm{~S}\left[\mathrm{M}^{+}+1\right]$ 401.1642; found 401.1641 .

\section{(S)-1-(2-(cyclopropylmethoxy)propyl)-3-(5-((5,6-dimethoxypyridin-3-yl)ethynyl)-4-} methylthiazol-2-yl)urea (32)

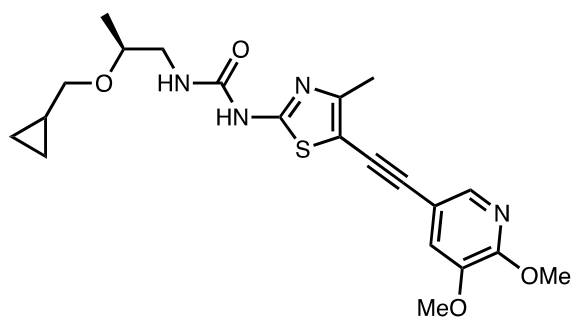

Compound 32 was synthesized in a manner similar to compound 13 using 1-[(2S)-2(cyclopropylmethoxy)propyl]-3-(5-iodo-4-methyl-thiazol-2-yl)urea and 2,3-dimethoxy-5((trimethylsilyl)ethynyl)pyridine to afford 32.HCl (19.5 mg, 49.3\%), ${ }^{1} \mathrm{H}$ NMR (300 MHz, MeOD) $\delta 7.83(\mathrm{~d}, J=1.8 \mathrm{~Hz}, 1 \mathrm{H}), 7.28(\mathrm{~d}, J=1.8 \mathrm{~Hz}, 1 \mathrm{H}), 3.96(\mathrm{~s}, 3 \mathrm{H}), 3.86(\mathrm{~s}, 3 \mathrm{H}), 3.64$ -3.61 (m, 1H), 3.47 - $3.26(\mathrm{~m}, 3 \mathrm{H}), 3.23-3.03(\mathrm{~m}, 1 \mathrm{H}), 2.37$ (s, 3H), $1.15(\mathrm{~d}, J=6.2 \mathrm{~Hz}$, $3 \mathrm{H}), 1.11-0.94(\mathrm{~m}, 1 \mathrm{H}), 0.53-0.50(\mathrm{~m}, 2 \mathrm{H}), 0.24-0.19(\mathrm{~m}, 2 \mathrm{H}) . \mathrm{HRMS}: \mathrm{m} / \mathrm{z}$ calcd for $\mathrm{C}_{21} \mathrm{H}_{26} \mathrm{~N}_{4} \mathrm{O}_{4} \mathrm{~S}\left[\mathrm{M}^{+}+1\right] 431.1745$; found 431.1747 .

\section{(S)-1-(2-(Cyclopropylmethoxy)propyl)-3-(5-((2-methoxypyridin-4-yl)ethynyl)-4-} methylthiazol-2-yl)urea (33)

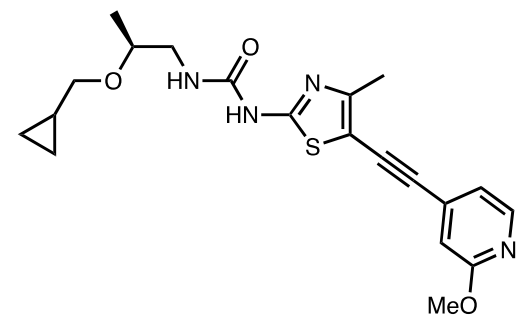

Compound 33 was synthesized in a manner similar to compound 13 using 1-[(2S)-2(cyclopropylmethoxy)propyl]-3-(5-iodo-4-methyl-thiazol-2-yl)urea and 2-methoxy-4- 
((trimethylsilyl)ethynyl)pyridine to afford $(S)$-2-(cyclopropylmethoxy)propan-1-amine 33.HCI (6.5 mg, 15\%); ${ }^{1} \mathrm{H}$ NMR (300 MHz, $\left.\mathrm{CDCl}_{3}\right) \delta 8.13(\mathrm{~d}, J=5.3 \mathrm{~Hz}, 1 \mathrm{H}), 6.91(\mathrm{~d}, J$ $=5.3 \mathrm{~Hz}, 1 \mathrm{H}), 6.80(\mathrm{~s}, 1 \mathrm{H}), 3.95(\mathrm{~s}, 3 \mathrm{H}), 3.74-3.50(\mathrm{~m}, 2 \mathrm{H}), 3.34-3.18(\mathrm{~m}, 3 \mathrm{H}), 2.45(\mathrm{~s}$, $3 \mathrm{H}), 1.20(\mathrm{~d}, J=6.0 \mathrm{~Hz}, 3 \mathrm{H}), 1.04-1.09(\mathrm{~m}, 1 \mathrm{H}), 0.65-0.41(\mathrm{~m}, 2 \mathrm{H}), 0.24-0.19(\mathrm{~m}, 2 \mathrm{H})$. HRMS: $\mathrm{m} / \mathrm{z}$ calcd for $\mathrm{C}_{20} \mathrm{H}_{24} \mathrm{~N}_{4} \mathrm{O}_{3} \mathrm{~S}\left[\mathrm{M}^{+}+1\right] 401.1642$; found 401.1637.

\section{(S)-1-(2-(Cyclobutylmethoxy)propyl)-3-(5-((2-methoxypyridin-4-yl)ethynyl)-4-} methylthiazol-2-yl)urea (34)

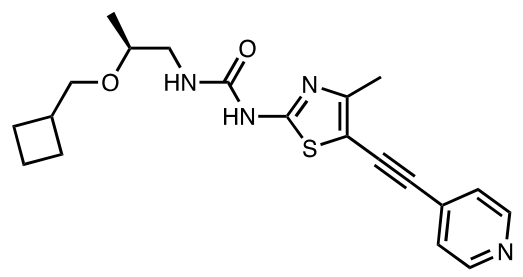

Compound 34 was synthesized in a manner similar to compound 6 using 47 and $(S)-2$ (cyclobutylmethoxy)propan-1-amine to afford 34.HCl (17 mg, 24.5\%). ${ }^{1} \mathrm{HNMR}$ (300 MHz, d6-DMSO); ${ }^{1} \mathrm{H}$ NMR $\delta 11.11$ (s, 1H), 8.90 (brs, 2H). 7.90 (brs, 2H), 6.83 (s, 1H), $3.46-3.10$ (m, 6H), 2.40 (s, 3H), $1.98-1.96$ (m, 6H), 1.06 (d, J=3.0 Hz, 3H). HRMS: $\mathrm{m} / \mathrm{z}$ calcd for $\mathrm{C}_{20} \mathrm{H}_{24} \mathrm{~N}_{4} \mathrm{O}_{2} \mathrm{~S}\left[\mathrm{M}^{+}+1\right] 385.1692$; found 385.1693 .

\section{The synthesis of (2S)-2-(cyclopropylmethoxy)propan-1-amine (48)}

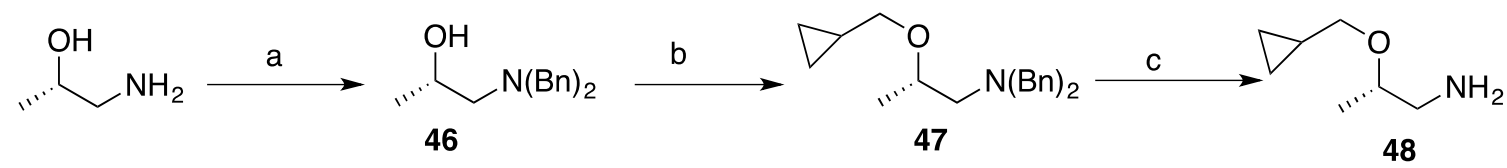

\section{Step 1}

To a stirred solution of (2S)-1-aminopropan-2-ol (2.5 g, $33.28 \mathrm{mmol})$ and benzaldehyde (6.76 mL, $66.56 \mathrm{mmol})$ in $\mathrm{MeOH}(22.5 \mathrm{~mL})$ and HOAc $(2.5 \mathrm{~mL})$ was added $\mathrm{NaCNBH}_{3}$ (2.614 g, $20.42 \mathrm{~mL}, 41.60 \mathrm{mmol}$ ) was slowly at room temperature. The resulting white suspension was heated at $65{ }^{\circ} \mathrm{C}$ for $1 \mathrm{~h}$. The reaction mixture was cooled to room temperature and the solvent was removed under reduced pressure. Water $(100 \mathrm{~mL})$ was added and the aqueous phase was extracted with EtOAc $(3 \times 50 \mathrm{~mL})$. The organic layers 
were dried over $\mathrm{Na}_{2} \mathrm{SO}_{4}$ and the solvent was removed under reduced pressure. The crude product was purified by ISCO eluting with EtOAc/hexanes $(0-50 \%))$ to afford compound $46(4.6 \mathrm{~g}, 54 \%)$ as a clear oil. ${ }^{1} \mathrm{HNMR}$ (300 $\left.\mathrm{MHz}, \mathrm{CDCl}_{3}\right) ; \delta 7.40-7.25(\mathrm{~m}, 10 \mathrm{H}), 3.43 \& 3.86(\mathrm{ABq}, J=15 \mathrm{~Hz}, 4 \mathrm{H}), 3.24(\mathrm{~s}, 1 \mathrm{H})$, $2.43(\mathrm{~d}, J=6 \mathrm{~Hz}, 2 \mathrm{H}), 1.07(\mathrm{~d}, J=6 \mathrm{~Hz}, 3 \mathrm{H})$; mass spectrum (ESI) m/z $256.4[\mathrm{M}+\mathrm{H}]^{+}$ $\left(\mathrm{C}_{17} \mathrm{H}_{21} \mathrm{NO}\right)$ requires 256.2 .

\section{Step 2}

To a stirred solution of compound 46 (2.25 g, $8.81 \mathrm{mmol})$ in anhydrous DMF $(10 \mathrm{~mL})$ was added $\mathrm{NaH}$ (845.6 mg, $35.24 \mathrm{mmol}$ ) portionwise at room temperature under nitrogen. The resulting suspension was stirred $30 \mathrm{~min}$ at RT and then heated at $75^{\circ} \mathrm{C}$ for $8 \mathrm{~h}$. The reaction mixture was cooled to room temperature and poured into water $(50 \mathrm{~mL})$ and sat $\mathrm{NaHCO}_{3}$ $(25 \mathrm{~mL})$ was added. The aqueous layer was extracted with ether/EtOAc (2:1, 2 times), dried over $\mathrm{Na}_{2} \mathrm{SO}_{4}$ and the solvent was removed under reduced pressure. The crude product was purified by ISCO eluting with EtOAc/hexanes (010\%)) to afford compound 47 (2.2 $\mathrm{g}, 81 \%)$ as an oil. ${ }^{1} \mathrm{HNMR}(300$ MHz, DMSO-d6); $\delta 7.36-7.20(\mathrm{~m}, 10 \mathrm{H}), 3.56(\mathrm{q}, J=14 \mathrm{~Hz}, 4 \mathrm{H}), 3.25-3.15(\mathrm{~m}, 2 \mathrm{H})$, 2.50 - $2.44(\mathrm{~m}, 1 \mathrm{H}), 2.46-2.44(\mathrm{~m}, 1 \mathrm{H}), 2.31-2.25(\mathrm{~m}, 1 \mathrm{H}), 0.98(\mathrm{~d}, J=6 \mathrm{~Hz}, 3 \mathrm{H}), 0.93$ $0.90(\mathrm{~m}, 1 \mathrm{H}), 0.44-0.39(\mathrm{~m}, 2 \mathrm{H}), 0.13$ - $0.08(\mathrm{~m}, 2 \mathrm{H})$; mass spectrum (ESI) m/z $310.5[\mathrm{M}$ $+\mathrm{H}]^{+}\left(\mathrm{C}_{21} \mathrm{H}_{27} \mathrm{NO}\right)$ requires 310.2 .

\section{Step 3}

A solution containing ammonium formate $(2.5 \mathrm{~g}, 38.8 \mathrm{mmol})$ and compound $47(2 \mathrm{~g}, 6.46$ mmol) in methanol $(50 \mathrm{~mL})$ was purged with $\mathrm{N}_{2}(5 \mathrm{~min})$ and $\mathrm{Pd}$ on C (wet, Degussa, 935 $\mathrm{mg}, 4.4 \mathrm{mmol}$ ) was added at room temperature. The solution was heated at $65^{\circ} \mathrm{C}$ for $1 \mathrm{~h}$. The reaction mixture was cooled and filtered over celite pad. The filtrate was concentrated under reduced pressure to afford compound 48 (720 mg, 86\%) a pale yellow oil. ${ }^{1} \mathrm{HNMR}$ (300 MHz, $\left.\mathrm{CDCl}_{3}\right) ; \delta 3.39$ - $3.35(\mathrm{~m}, 1 \mathrm{H}), 3.30-3.17$ (m, 2H), 2.59 (brs, 2H), 0.97 (d, $J=$ $6 \mathrm{~Hz}, 3 \mathrm{H}), 0.94-0.92$ (m, 1H), $0.46-0.41$ (m, 2H), $0.16-0.12(\mathrm{~m}, 2 \mathrm{H})$.

\section{Description of Biochemical Assays}


PI3K Inhibition Assays The compounds of interest were dissolved in DMSO to make 10 $\mu \mathrm{M}$ initial stock solutions. Serial dilutions in DMSO were then made to obtain the final solutions for the assay. Using a Biomek FX from Beckman Coulter, a $1.5 \mu \mathrm{L}$ aliquot aliquot of DMSO or inhibitor in DMSO was added to each individual well (hereafter, "test well") in a 96 well polystyrene plate [Corning, Costar Item No. 3697]. Using a Titertek Multidrop, $50 \mu \mathrm{L}$ of ATP Mix [50 mM HEPES (pH 7.5), 3 mM MgCl2, 100 mM NaCl, 2 mM DTT, $1 \mathrm{mM}$ EGTA, $0.03 \%$ CHAPS, and ATP (100 $\mu \mathrm{Ci} / \mu \mathrm{mol} 33 \mathrm{P}-\mathrm{ATP})$ (See Table 1 for ATP concentrations, each equal to $\mathrm{Km}$ )] was added to each well. To initiate the reaction, $50 \mu \mathrm{L}$ of Reaction Mixture [50 mM HEPES (pH 7.5), 3 mM MgCl2, 100 mM NaCl, 2 mM DTT, $1 \mathrm{mM}$ EGTA, 0.03\% CHAPS, $20 \mu \mathrm{M}$ PIP2 (phosphatidylinositol(4,5)-bisphosphate diC16 (PI(4,5)P2; Avanti Polar Lipids, Cat. No. 840046P) and PI3K isoform of interest (See Table 1 for isoform concentrations)] was added to each well, followed by incubating the wells for 15 min at room temperature. Table 1 PI3K Isoform PI3K $\alpha$ PI3K $\beta$ PI3K $\gamma$ PI3K $\delta$ Final ATP concentration (equal to $\mathrm{Km}$ ) $5 \mu \mathrm{M} 27 \mu \mathrm{M} 10 \mu \mathrm{M} 7 \mu \mathrm{M}$ Final enzyme concentration $4 \mathrm{nM} 20 \mathrm{nM} 6 \mathrm{nM} 6 \mathrm{nM}$ After incubation, the reactions in each well were quenched by addition of $50 \mu \mathrm{L}$ of stop solution [30\% TCA/water, $10 \mathrm{mM} \mathrm{ATP]}$. Each quenched reaction mixture was then transferred to a 96 well glass fiber filter plate [Corning, Costar Item No. 3511]. The plate was vacuum-filtered and washed three times with $150 \mu \mathrm{L}$ of 5\% TCA/water in a modified Bio-Tek Instruments ELX-405 Auto Plate Washer. $50 \mu \mathrm{L}$ of scintillation fluid was added to each well and the plate read on a Perkin-Elmer TopCountTM NXT liquid scintillation counter to obtain 33P-counts. After removing mean background values for all of the data points, $\mathrm{Ki}(\mathrm{app})$ data were calculated from non-linear regression analysis of the initial rate data using the Prism software package (GraphPad Prism, GraphPad Software, San Diego California, USA). The data were fit to the Morrison equation for competitive tight binding $\mathrm{Ki}$ as described by Copeland (Reference: RA Copeland, Enzymes, 2nd edition, Wiley, 2000, Equation 9.6). Compound potencies were determined in singlicate. Average Kis are be reported for compounds that have multiple determinations. The Average of the Robust MSRs for PI3K $\alpha, \beta, \gamma, \delta$ were determined to be $3.2,3.0,3.1$, and 2.7 respectively. 
(Reference :JBiomolScreen_MSR, AMC_Robust_Statistics, Minimum Significant Ratio A Statistic to Assess Assay Variability)

Table 6

\begin{tabular}{|l|l|l|l|l|}
\hline PI3K Isoform & PI3K $\alpha$ & PI3K $\beta$ & PI3K $\gamma$ & PI3K $\delta$ \\
\hline $\begin{array}{l}\text { Final ATP concentration }(\mu \mathrm{M}) \\
\text { (equal to Km) }\end{array}$ & 5 & 27 & 10 & 7 \\
\hline Final enzyme concentration $(\mathrm{nm})$ & 4 & 20 & 6 & 6 \\
\hline
\end{tabular}

\section{Description of Cellular Assays}

\section{Materials}

THP-1 were obtained from ATCC. DMEM, GultaMax, Penicillin/Streptomycin, 2mercaptoethanol, Hepes solution 1M, TrypLE Express, 7.5\% BSA, Fraction V were obtained from Invitrogen. Heat Inactivated FBS from ThermoFisher Scientific. Recombinant human MCP-1 from PeproTech; AffiniPure F(ab')2 Fragment Goat AntiHuman IgM from Jackson Immuno Research Labs; CellTiter-Glo luminescent cell viability assay from Promega; Phospho-Akt antibody (S473) AlexaFluor647 conjugated from Cell Signaling Technology; Formaldehyde 37\% from Sigma; Methanol from JT Baker; 96-well plates, black with clear bottom and 96 well $\mathrm{V}$ bottom polypropylene plates from Costar.

\section{Air Pouch Protocol}

Male Balb/c mice (8 to 10 weeks) were obtained from Jackson Laboratories and subcutaneous pouches were created on the dorsum by two serial injections of air $(5 \mathrm{~mL}$ and $3 \mathrm{~mL}$ ) at 6 and 3 days prior to compound administration. Animals were then treated orally with a single administration of compound $\mathbf{1 4}$ prepared as a suspension in $0.2 \%$ methylcellulose $(\mathrm{MC}) / 1 \%$ sodium lauryl sulfate (SLS) or with vehicle alone at a final dosing volume of $10 \mathrm{~mL} / \mathrm{kg}$. One hour after treatment with compound 14, each mouse received an injection of $\operatorname{IL}-8(1 \mu \mathrm{g})$ or saline directly into the pouch to 
induce chemotaxis of neutrophils. Four hours later, mice were euthanized and cells were extracted from the pouch by lavage. Cells were pelleted, resuspended in $1 \mathrm{~mL} 1 \mathrm{X}$ BD lyse/fix buffer, stained with antibodies and then neutrophil numbers were determined by FACS. Cells were stained with an antibody cocktail containing 1:200 anti-mouse CD11bFITC, 1:400 anti-mouse Gr-1 APC and 1:200 Fc block(Cd16/32) for 30 minutes at room temperature. Plates were read on a BD FACS Calibur. \% of CD11b/Gr-1 double positive neutrophils was determined via Flow Jo based analysis. Total cell counts were determined using the Guava via count protocol. Plasma and brain tissue were collected for compound concentration analysis. Concentrations were determined using a high performance liquid chromatography/tandem mass spectrometry (HPLC/MS/MS) method.

\section{Crystallographic Information.}

Methods: PI3K gamma protein was expressed, purified and crystallized as described by Walker et al.2 Briefly, PI3K (K1432-L1767) was expressed as a fusion with an uncleavable C-terminal (His)6 tag in SF21 insect cells. The protein was purified using a combination of metal-affinity (Talon resin), cation-exchange (Poros 20HS resin), and gel filtration chromatography (S-200 resin). The final buffer was $20 \mathrm{mM}$ Tris, $0.5 \mathrm{mM}$ ammonium sulphate, $1 \%$ ethylene glycol, $0.02 \%$ CHAPS, 5 mM DTT, $\mathrm{pH}$ 7.2. Crystals were grown by vapor diffusion using a reservoir solution containing $100 \mathrm{mM}$ Tris buffer, $\mathrm{pH} 8.5,25 \%$ w/v PEG 3350, $200 \mathrm{mM}$ lithium sulfate, $10 \mathrm{mM}$ DTT and $10 \mathrm{mM}$ EDTA. Inhibitor complexes were prepared by soaking PI3K crystals for 12-24 hours in the reservoir buffer supplemented with $13 \% \mathrm{w} / \mathrm{v}$ glycerol and the inhibitor at a concentration of $1 \mathrm{mM}$. Prior to data collection the crystals were flash frozen directly in the soaking solution. Xray diffraction data were collected at the 5.0.2 beamline at the Advanced Light Source (ALS) and processed/scaled with Global Phasing autoPROC.3. The starting model was obtained from the RCSB4 (entry 1E7U) whose structure was reported by Walker et al.2 The structure was built with Coot5 and refined using the Global Phasing BUSTER package (Bricogne G., Blanc E., Brandl M., Flensburg C., Keller P., Paciorek W., Roversi P, Sharff A., Smart O.S., Vonrhein C., Womack T.O. (2017). BUSTER version X.Y.Z. Cambridge, United Kingdom: Global Phasing Ltd. 
Table 6. Kinase selectivity profile of compound $4,14,23,31$ and 32 against a diverse panel of kinases

\begin{tabular}{|l|l|}
\hline Kinase & $\mathbf{K}_{i} \boldsymbol{\mu} \mathbf{M}$ \\
\hline CDK2 & $>4$ \\
\hline FLT3 & $>4$ \\
\hline GSK3b & $>4$ \\
\hline IRAK4 & $>4$ \\
\hline JAK2 & $>4$ \\
\hline JNK3 & $>4$ \\
\hline KDR & $>4$ \\
\hline MET & $>4$ \\
\hline PKA & $>4$ \\
\hline PLK1 & $>4$ \\
\hline ROCK1 & $>4$ \\
\hline SRC & $>4$ \\
\hline SYK & $>4$ \\
\hline
\end{tabular}

\section{MDCK-MDR1 Permeability Assay}

Permeability measurements were conducted according to the Cyprotex protocol using the MDCKMDR1 cell line. Cells between passage numbers $6-30$ were seeded onto a Multiscreen plate at a cell density of $3.4 \AA \sim 105$ cells $/ \mathrm{cm} 2$ and cultured for 3 days before permeability studies were conducted. The cells in this assay form a cohesive sheet of a single cell layer, filling the surface area of the culture dish, also known as a confluent monolayer, and on day four, the test compound was added to the apical side of the membrane; the transport of the compound across the monolayer was monitored over a time period of $60 \mathrm{~min}$. Test compounds were dissolved in DMSO at a concentration of $10 \mu \mathrm{M}$. 
The dosing solutions were prepared by diluting the test compounds with assay buffer, $\mathrm{pH}$ 7.4 , at a final concentration of $5 \mu \mathrm{M}$. For the assessment of the apical to basolateral ("A-B") permeability, buffer was removed from the apical compartment and replaced with the test compound dosing solution with or without the permeability glycoprotein (P-gp) inhibitor elacridar $(2 \mu \mathrm{M})$. For the assessment of basolateral to apical ("B-A") permeability, buffer was removed from the companion plate and replaced with the test compound dosing solution. Incubations were carried out in duplicates at $37{ }^{\circ} \mathrm{C}$ in an atmosphere of $5 \% \mathrm{CO}_{2}$ with a relative humidity of $95 \%$. Each assay included the reference markers propranolol (high permeability) and prazosin (P-gp substrate). After incubation for $60 \mathrm{~min}$, apical and basolateral samples were diluted, and the test compounds were quantified by LC/MS/MS using an 8-point calibration in the range 0.0039 to $3 \mu \mathrm{M}$ with the appropriate dilution of the samples (receiver dilution factor $=1$, donor and $\mathrm{C} 0$ dilution factor $=10)$. The permeability coefficient (Papp) for each compound was calculated from the following equation: Papp $=(\mathrm{dQ} / \mathrm{dt}) /(\mathrm{C} 0 \AA \sim \mathrm{S})$, where $\mathrm{dQ} / \mathrm{dt}$ is the rate of permeation of the drug across the cells, $\mathrm{C} 0$ is the donor compartment concentration at time zero, and $\mathrm{S}$ is the area of the cell monolayer. The percent recovery was measured for all incubation conditions. These measurements did not reveal unacceptable compound/plate binding or compound accumulation in the cell monolayer. 